Supporting information

\title{
Rearrangements of betulin core. Synthesis of terpenoids possessing the bicyclo[3.3.1] nonane fragment by rearrangement of lupane-type epoxides.
}

Zbigniew Pakulski, ${ }^{*}, a$ Piotr Cmoch, ${ }^{a}$ Anna Korda, ${ }^{a}$ Roman Luboradzki, ${ }^{b}$ Katarzyna Gwardiak, ${ }^{a}$ Romuald Karczewski ${ }^{a}$

${ }^{a}$ Institute of Organic Chemistry, Polish Academy of Sciences, Kasprzaka 44/52, 01-224 Warsaw, Poland

${ }^{b}$ Institute of Physical Chemistry, Polish Academy of Sciences, Kasprzaka 44/52, 01-224 Warsaw, Poland

\begin{tabular}{|l|c|}
\hline Table of contents & Page \\
\hline Crystal structure determination of compounds 29 and 30 & S2-S3 \\
\hline Key HMBC and NOE correlations & S4 \\
\hline NMR spectra of compounds 10, 11, 13-20, 22-31, 33, and 34 & S5-S46 \\
\hline
\end{tabular}


The structure of compound $\mathbf{2 9}$ was determined on a crystal prepared from a chloroform / methanol solvent system by slow evaporation at room temperature. The X-ray data have been deposited at the Cambridge Crystallographic Data Centre (CCDC 1999008).

Table S1. Crystal data for 29.

\begin{tabular}{|l|l|}
\hline Empirical formula & $\mathrm{C}_{32} \mathrm{H}_{52} \mathrm{O}_{3}$ \\
\hline Moiety formula & $\mathrm{C}_{32} \mathrm{H}_{52} \mathrm{O}_{3}$ \\
\hline Formula weight & 484.74 \\
\hline CCDC No. & CCDC 1999008 \\
\hline Wavelength & 1.54184 \\
\hline Crystal system & monoclinic \\
\hline Space group & $P 21$ \\
\hline \multirow{3}{*}{ Unit cell dimensions } & $a=12.1451(3) \AA$ \\
\cline { 2 - 2 } & $b=7.5080(2) \AA$ \\
\cline { 2 - 3 } & $\mathrm{C}=30.4448(6) \AA$ \\
\hline Volume & $2763.58(11) \AA^{3}$ \\
\hline$Z$ & 4 \\
\hline Density Calc. & $1.165 \mathrm{~g} / \mathrm{cm}^{3}$ \\
\hline Absorption coefficient & $0.553 \mathrm{~mm}{ }^{-1}$ \\
\hline F(000) & 1072 \\
\hline Crystal & Colorless block \\
\hline Crystal size & $0.2 \times 0.03 \times 0.03 \mathrm{~mm}$ \\
\hline Index ranges & $-14 \leq \mathrm{h} \leq 12,-9 \leq \mathrm{k} \leq 8,-36 \leq 1 \leq 36$ \\
\hline $\begin{array}{l}\text { Reflections collected } \\
\text { (all / independent) }\end{array}$ & $11665 / 7579\left[R_{\text {int }}=0.0296\right]$ \\
\hline Absorption correction & multi-scan \\
\hline Refinement method & Full-matrix least-squares on $F^{2}$ \\
\hline Restraints / parameters & $1 / 647$ \\
\hline Goodness-of-fit on $F^{2}$ & 1.074 \\
\hline Final R indices $\left[F^{2}>2 \sigma\left(F^{2}\right)\right]$ & $R 1=0.0382, \mathrm{wR} 2=0.0966$ \\
\hline$R$ indices (all data) & $R 1=0.0469, \mathrm{wR} 2=0.1026$ \\
\hline
\end{tabular}

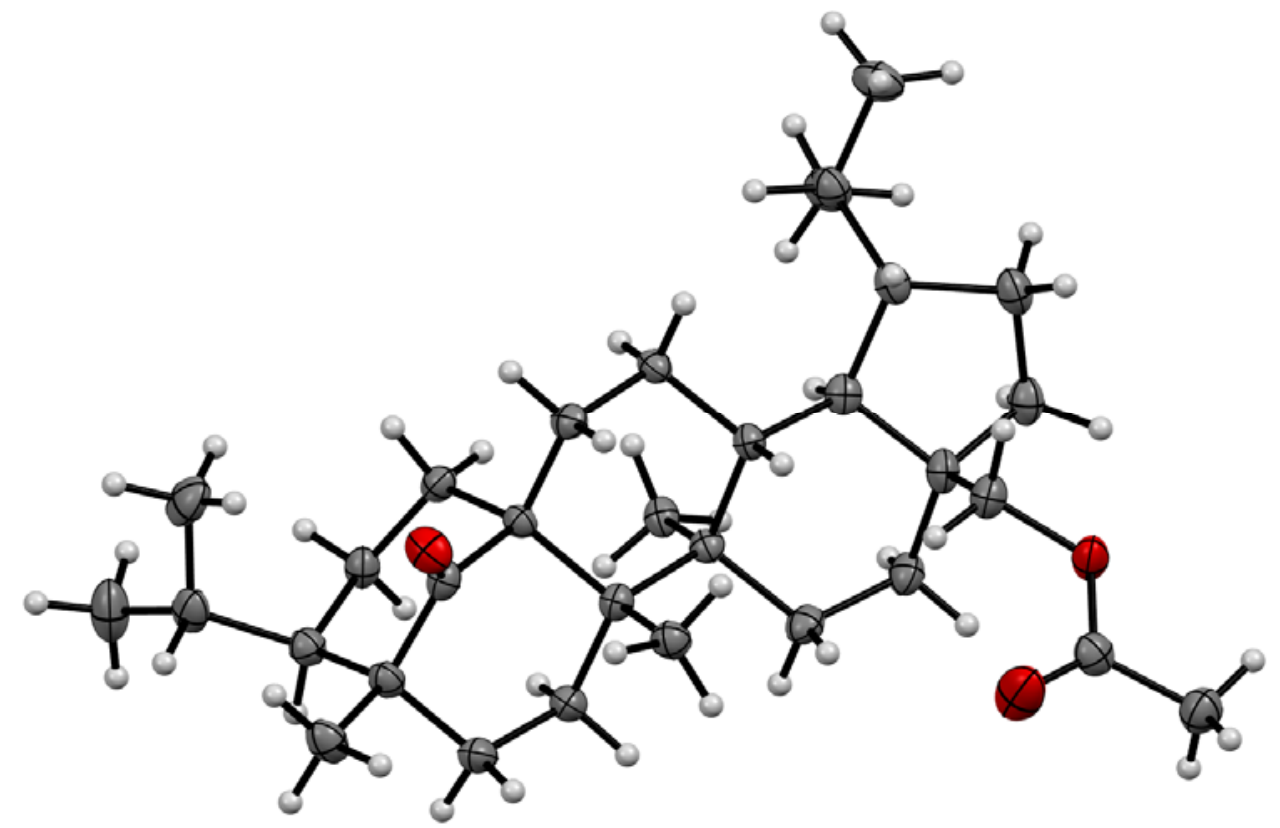

Figure S1. ORTEP diagram of compound 29 (CCDC 1999008). Contour probability level: 50\%. 
The structure of compound $\mathbf{3 0}$ was determined on a crystal prepared from a chloroform / methanol solvent system by slow evaporation at room temperature. The X-ray data have been deposited at the Cambridge Crystallographic Data Centre (CCDC 2038963).

Table S2. Crystal data for 30.

\begin{tabular}{|c|c|c|}
\hline Empirical formula & \multicolumn{2}{|l|}{$\mathrm{C}_{31} \mathrm{H}_{48} \mathrm{O}_{2}$} \\
\hline Moiety formula & \multicolumn{2}{|l|}{$\mathrm{C}_{31} \mathrm{H}_{48} \mathrm{O}_{2}$} \\
\hline Formula weight & \multicolumn{2}{|l|}{452.69} \\
\hline CCDC No. & \multicolumn{2}{|l|}{ CCDC 2038963} \\
\hline Wavelength & \multicolumn{2}{|l|}{1.54184} \\
\hline Crystal system & \multicolumn{2}{|l|}{ monoclinic } \\
\hline Space group & \multicolumn{2}{|l|}{$P 2_{1}$} \\
\hline \multirow{3}{*}{ Unit cell dimensions } & $a=6.96533(15) \AA$ & \\
\hline & $b=12.3846(3) \AA$ & $\beta=98.006(2)^{\circ}$ \\
\hline & $c=15.4756(4) \AA$ & \\
\hline Volume & \multicolumn{2}{|l|}{$1321.95(5) \AA^{3}$} \\
\hline $\mathrm{Z}$ & \multicolumn{2}{|l|}{2} \\
\hline Density Calc. & \multicolumn{2}{|l|}{$1.137 \mathrm{~g} / \mathrm{cm}^{3}$} \\
\hline Absorption coefficient & \multicolumn{2}{|l|}{$0.518 \mathrm{~mm}^{-1}$} \\
\hline $\mathrm{F}(000)$ & \multicolumn{2}{|l|}{500} \\
\hline Crystal & \multicolumn{2}{|l|}{ Colorless block } \\
\hline Crystal size & \multicolumn{2}{|c|}{$0.6 \times 0.06 \times 0.05 \mathrm{~mm}$} \\
\hline Index ranges & \multicolumn{2}{|c|}{$-6 \leq \mathrm{h} \leq 8,-15 \leq \mathrm{k} \leq 13,-18 \leq 1 \leq 18$} \\
\hline $\begin{array}{l}\text { Reflections collected } \\
\text { (all / independent) }\end{array}$ & \multicolumn{2}{|c|}{$6842 / 3761\left[\mathrm{R}_{\text {int }}=0.0233\right]$} \\
\hline Absorption correction & \multicolumn{2}{|l|}{ multi-scan } \\
\hline Refinement method & \multicolumn{2}{|c|}{ Full-matrix least-squares on $F^{2}$} \\
\hline Restraints / parameters & \multicolumn{2}{|l|}{$0 / 306$} \\
\hline Goodness-of-fit on $F^{2}$ & \multicolumn{2}{|l|}{1.049} \\
\hline Final $\mathrm{R}$ indices $\left[F^{2}>2 \sigma\left(F^{2}\right)\right]$ & \multicolumn{2}{|c|}{$R_{1}=0.0334, \mathrm{wR}_{2}=0.0910$} \\
\hline$R$ indices (all data) & \multicolumn{2}{|c|}{$R_{1}=0.0340, \mathrm{wR}_{2}=0.0919$} \\
\hline
\end{tabular}

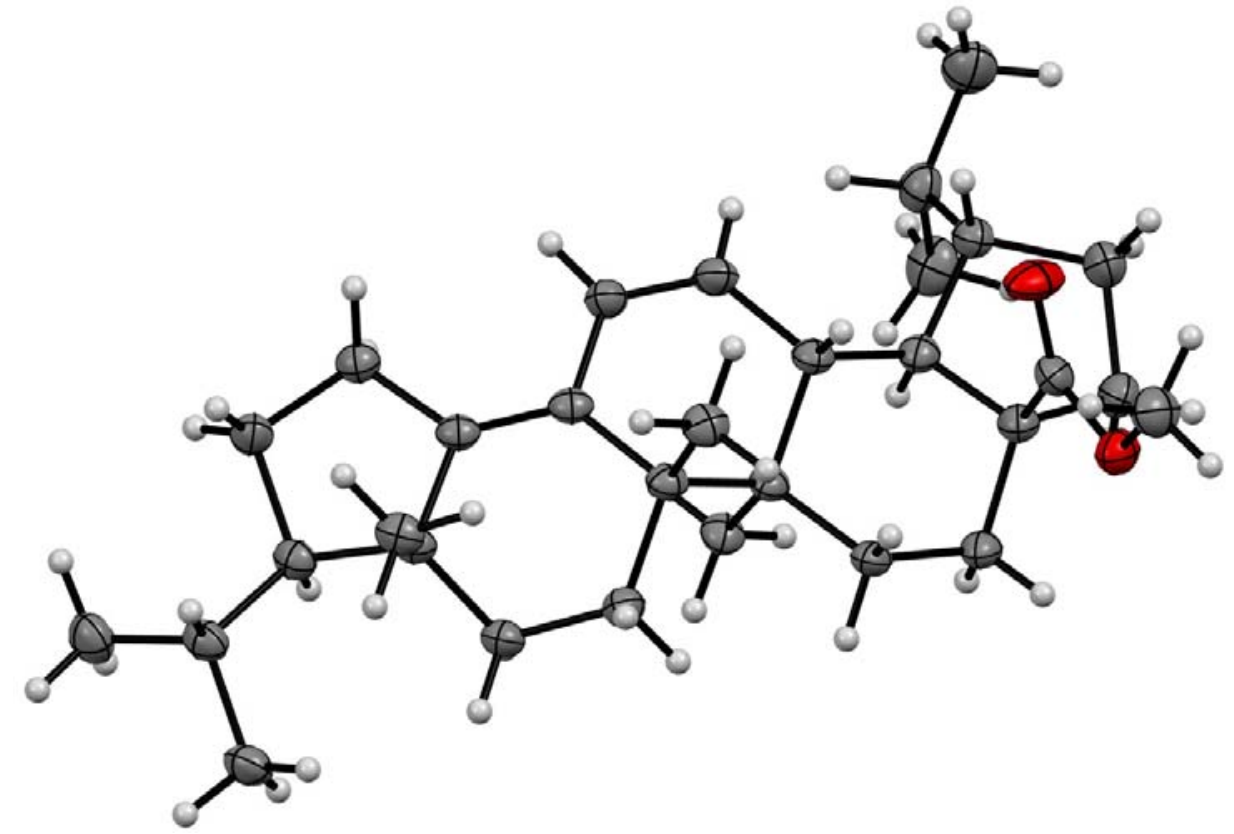

Figure S2. ORTEP diagram of compound 30 (CCDC 2038963). Contour probability level: 50\%. 
Table S3. Key HMBC (------) and NOE (------) correlations.

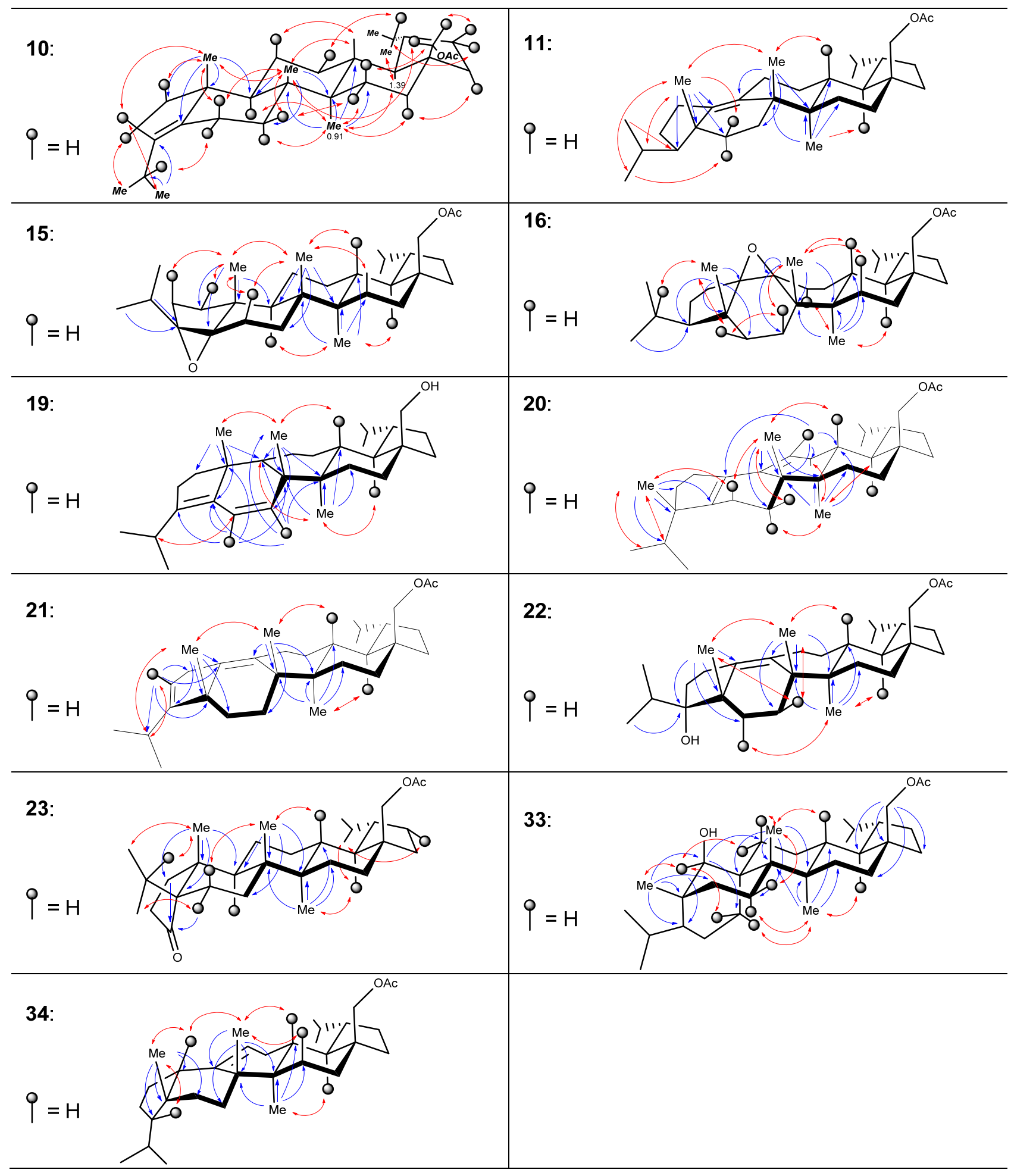


${ }^{1} \mathrm{H}$ NMR $\left(600 \mathrm{MHz}, \mathrm{CDCl}_{3}\right)$

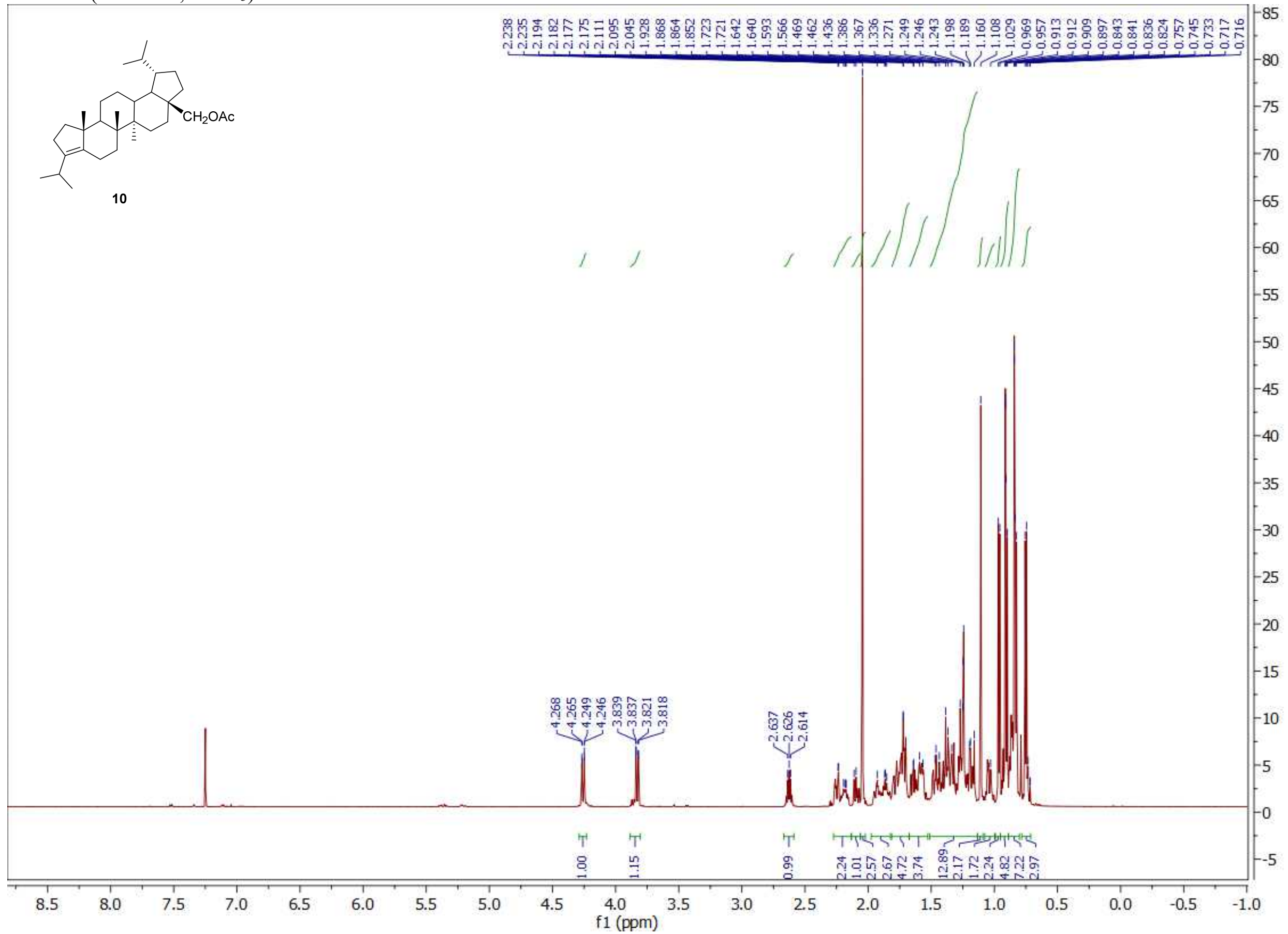


${ }^{13} \mathrm{C}\left\{{ }^{1} \mathrm{H}\right\}$ NMR $\left(150 \mathrm{MHz}, \mathrm{CDCl}_{3}\right)$

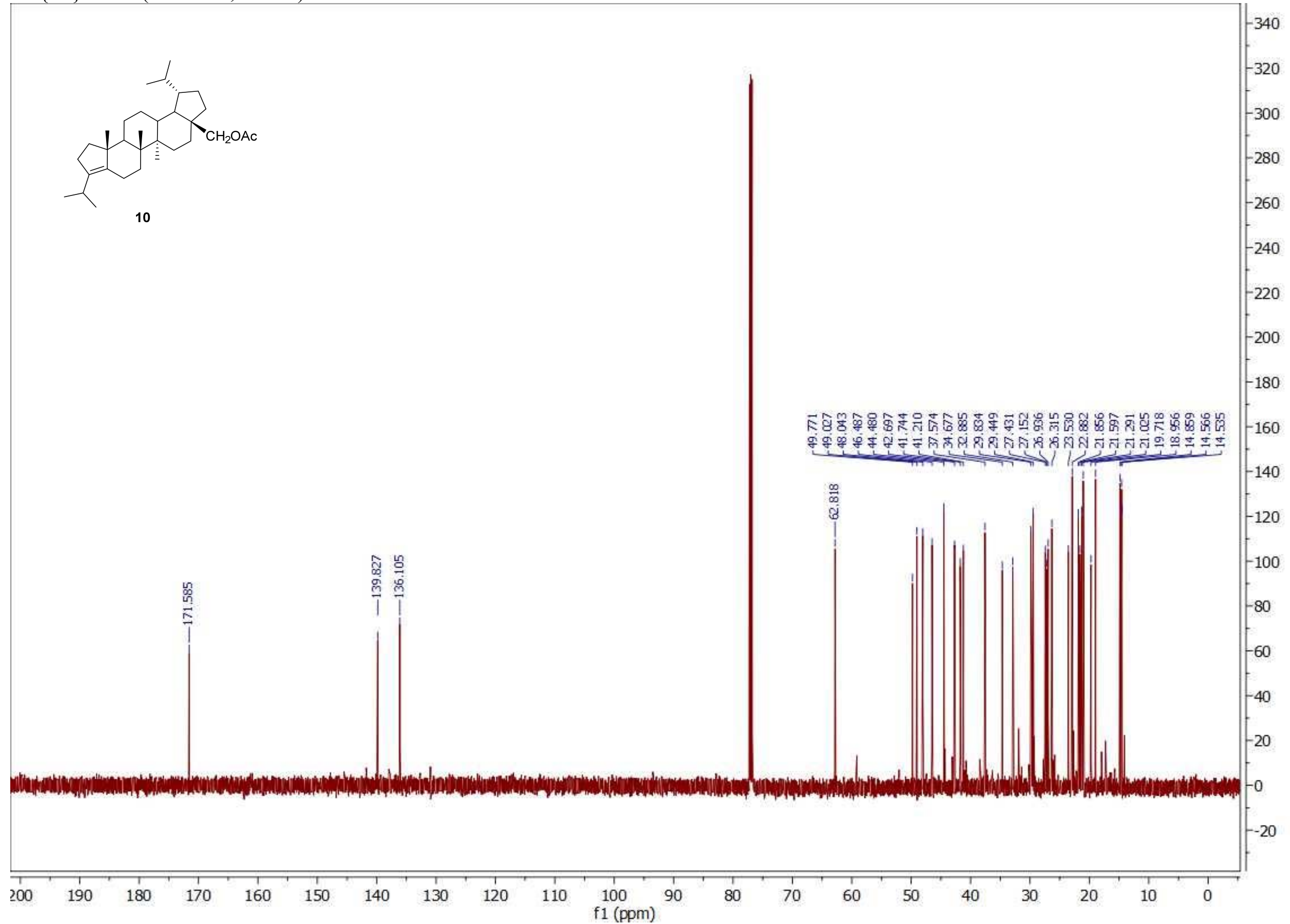


${ }^{1} \mathrm{H}$ NMR $\left(600 \mathrm{MHz}, \mathrm{CDCl}_{3}\right)$

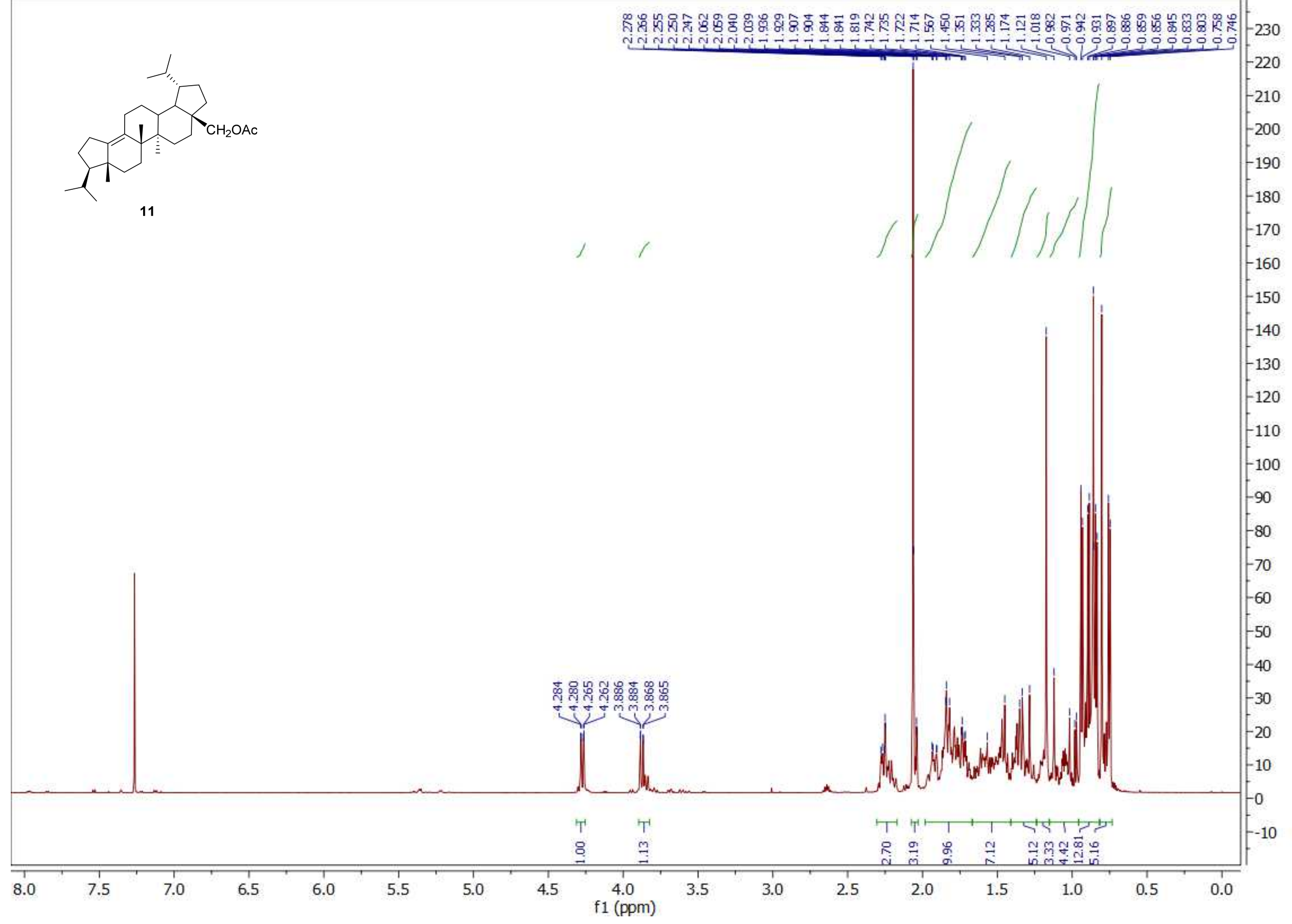


${ }^{13} \mathrm{C}\left\{{ }^{1} \mathrm{H}\right\} \mathrm{NMR}\left(150 \mathrm{MHz}, \mathrm{CDCl}_{3}\right)$

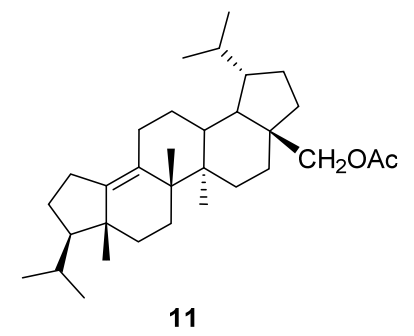

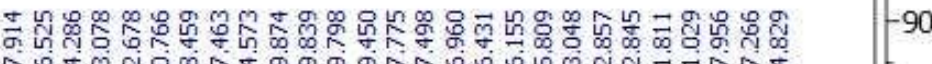

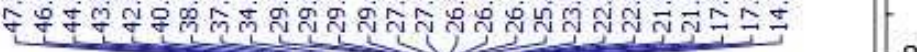

$\stackrel{0}{\infty} \frac{m}{a i}$

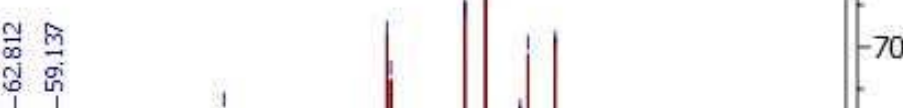

กั่
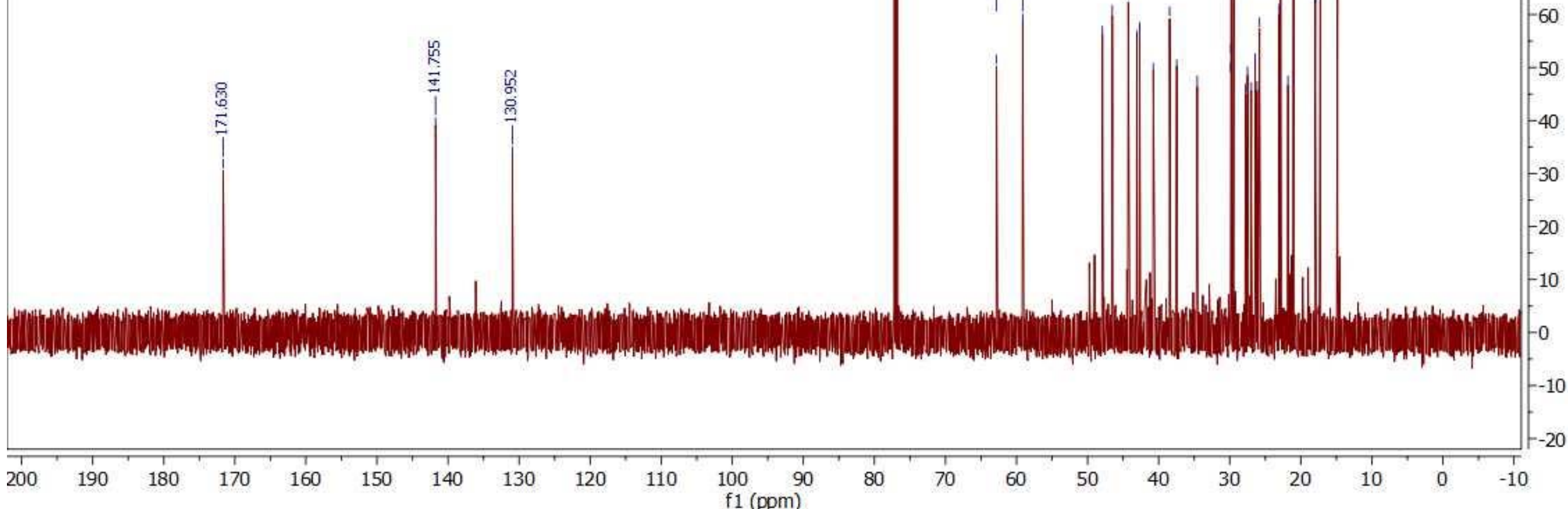
${ }^{1} \mathrm{H}$ NMR $\left(500 \mathrm{MHz}, \mathrm{CDCl}_{3}\right)$

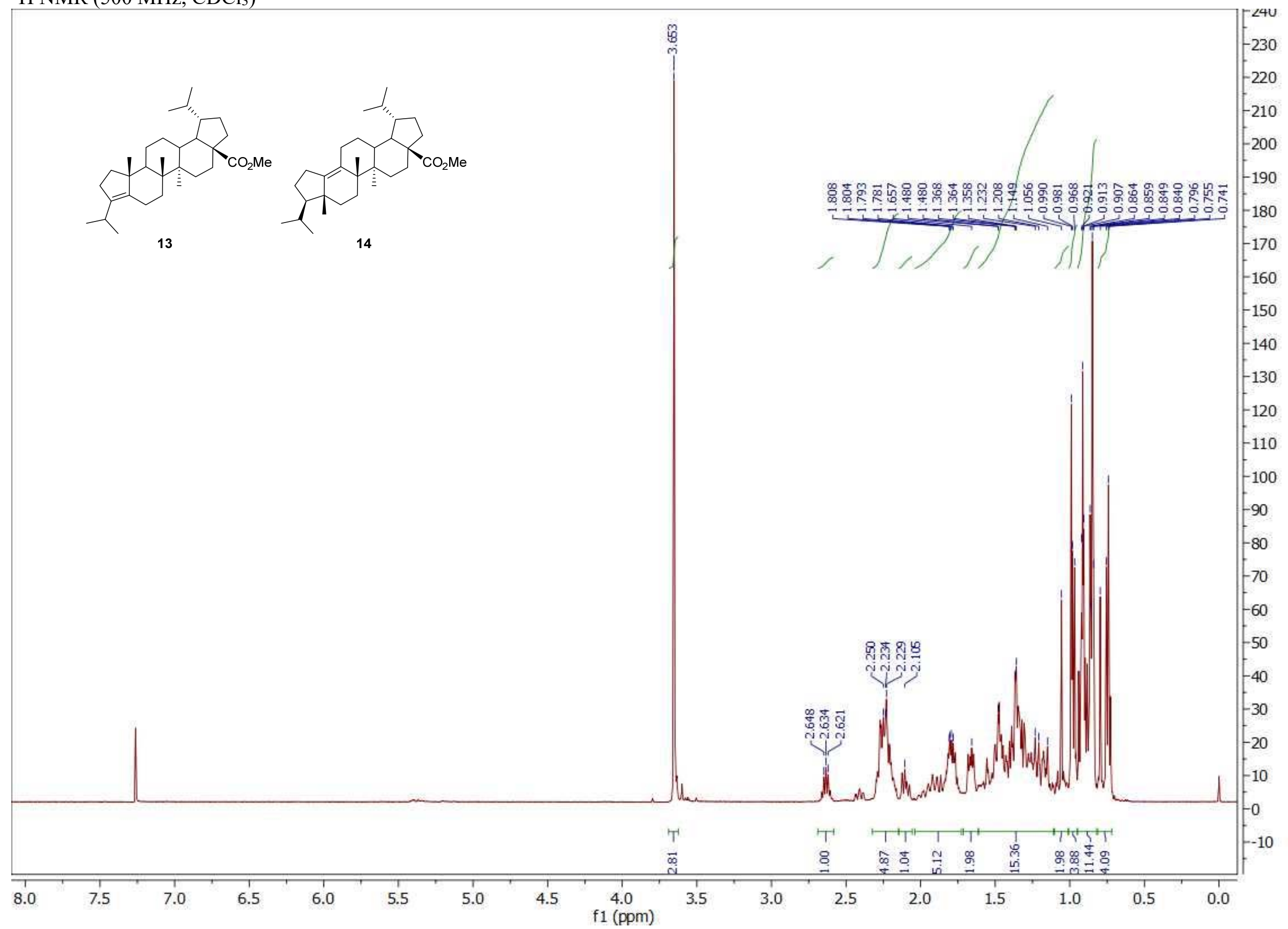


${ }^{13} \mathrm{C}\left\{{ }^{1} \mathrm{H}\right\}$ NMR $\left(125 \mathrm{MHz}, \mathrm{CDCl}_{3}\right)$
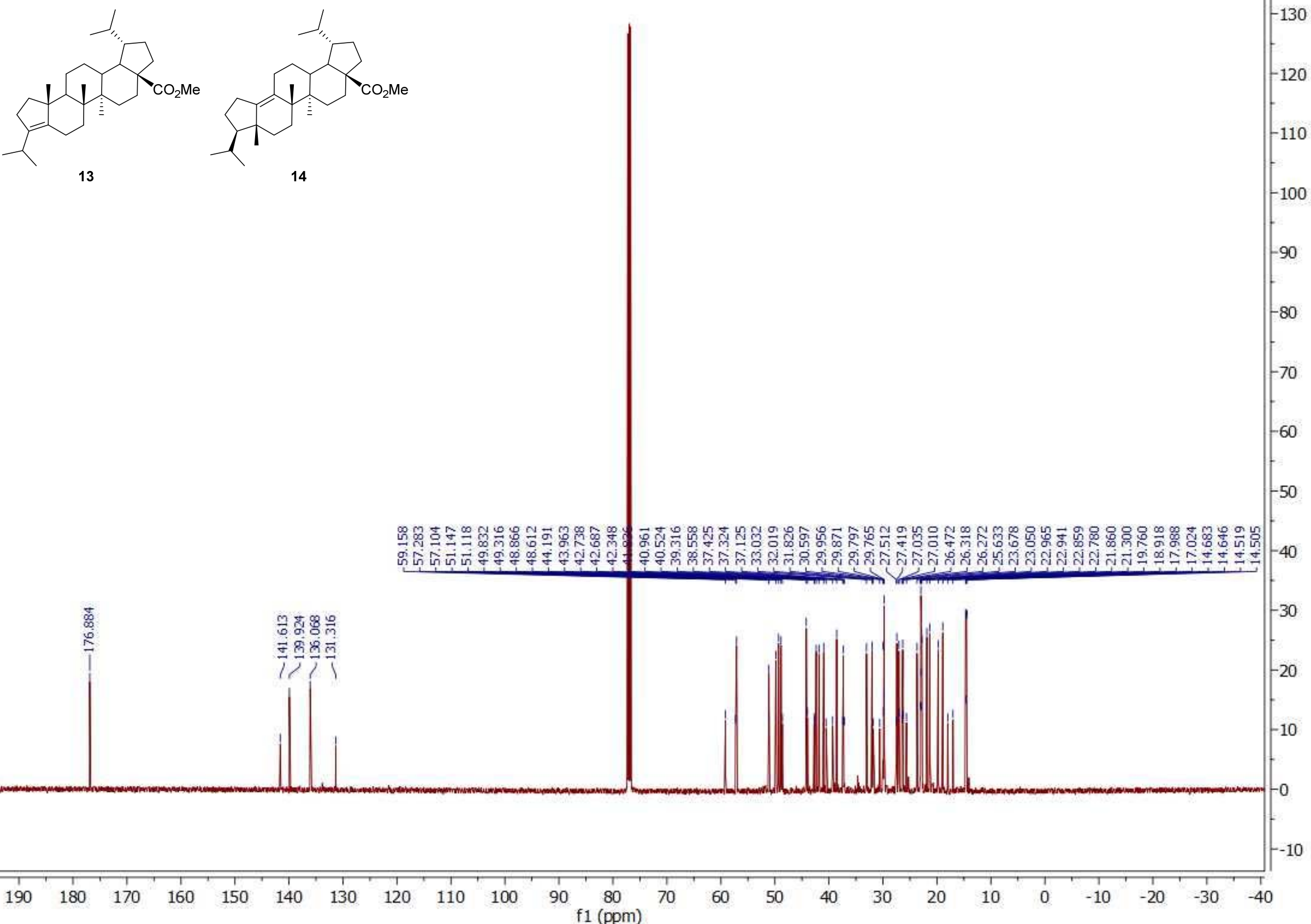
${ }^{1} \mathrm{H}$ NMR $\left(600 \mathrm{MHz}, \mathrm{CDCl}_{3}\right)$

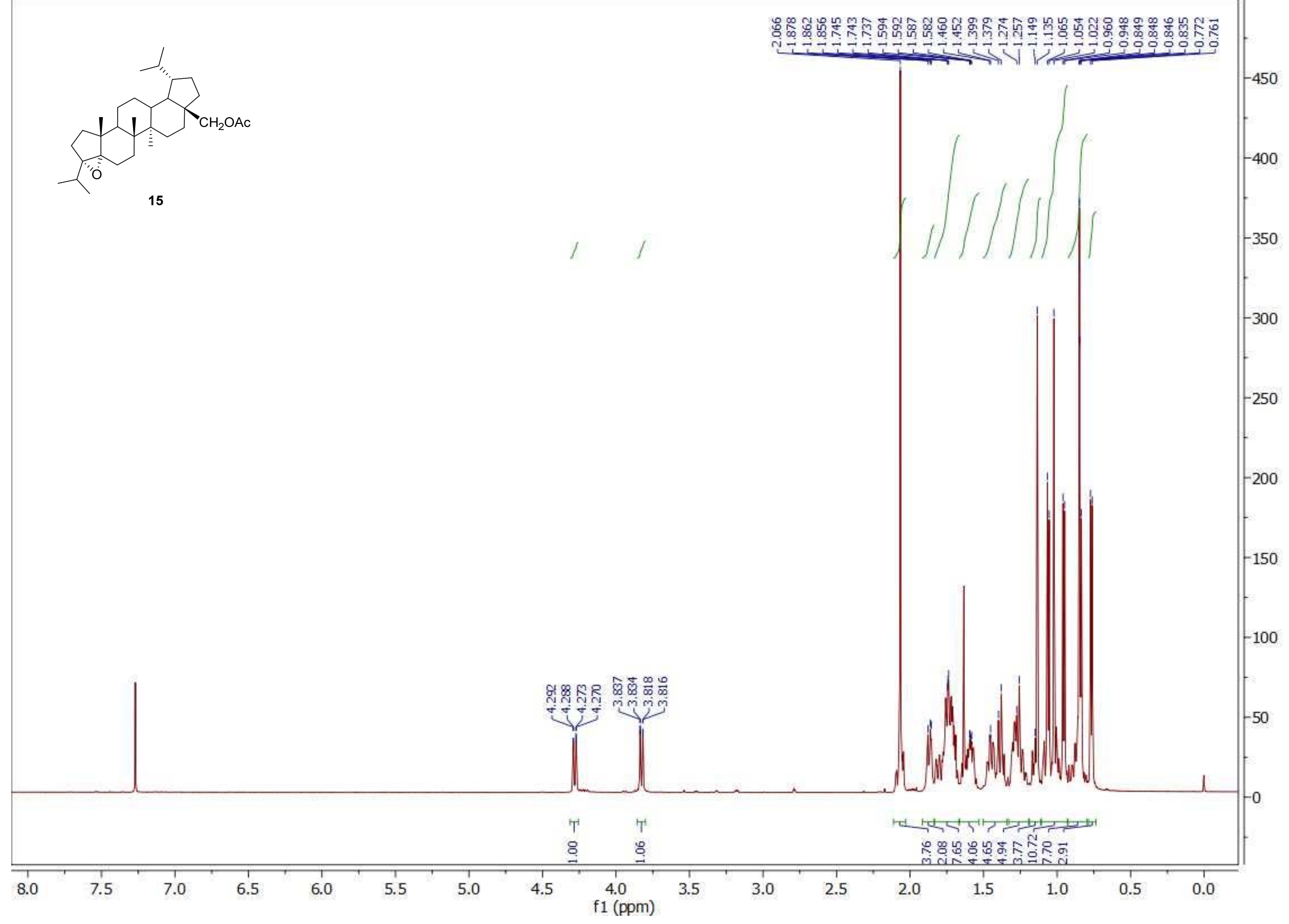


${ }^{13} \mathrm{C}\left\{{ }^{1} \mathrm{H}\right\}$ NMR $\left(150 \mathrm{MHz}, \mathrm{CDCl}_{3}\right)$
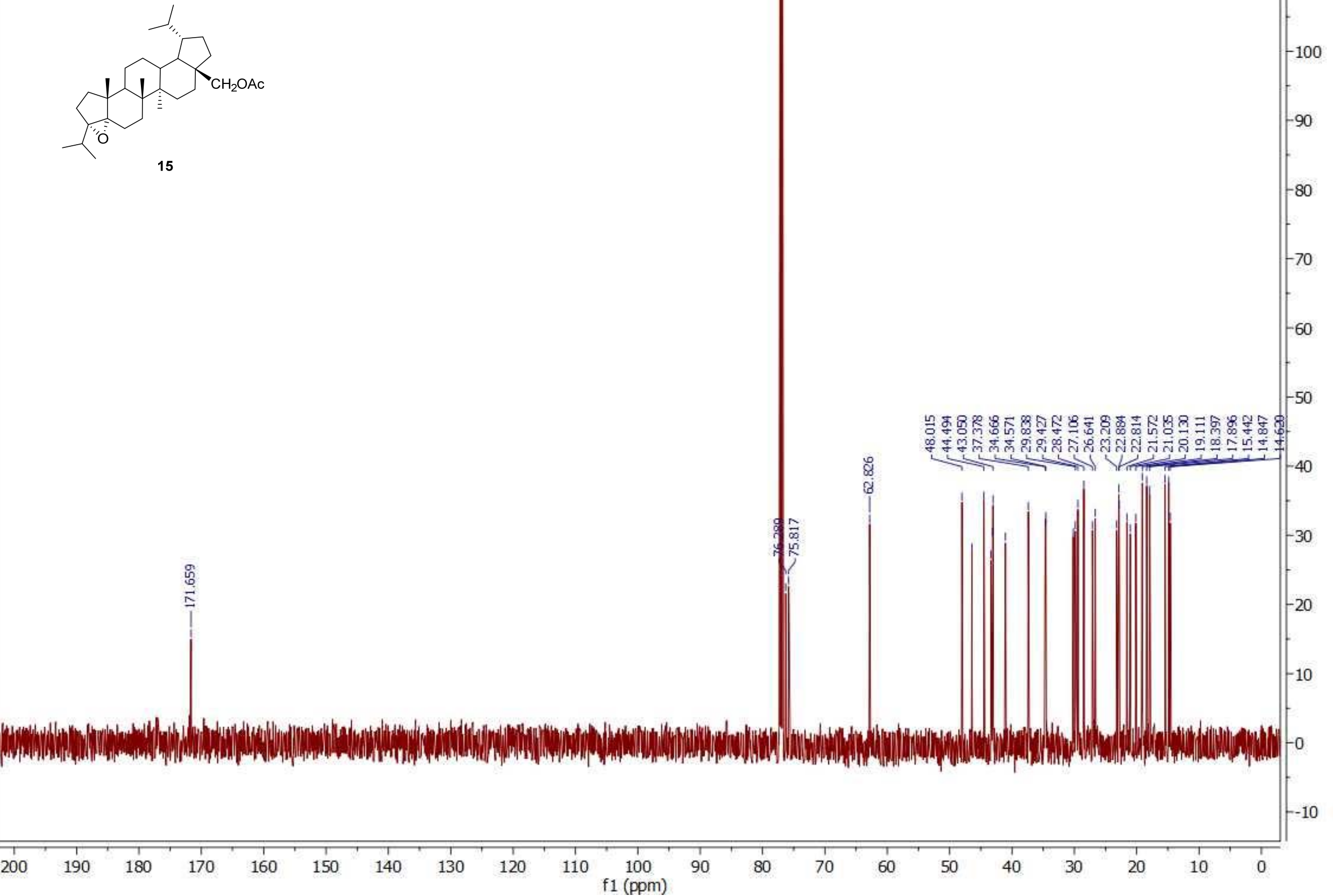
${ }^{1} \mathrm{H}$ NMR $\left(600 \mathrm{MHz}, \mathrm{CDCl}_{3}\right)$

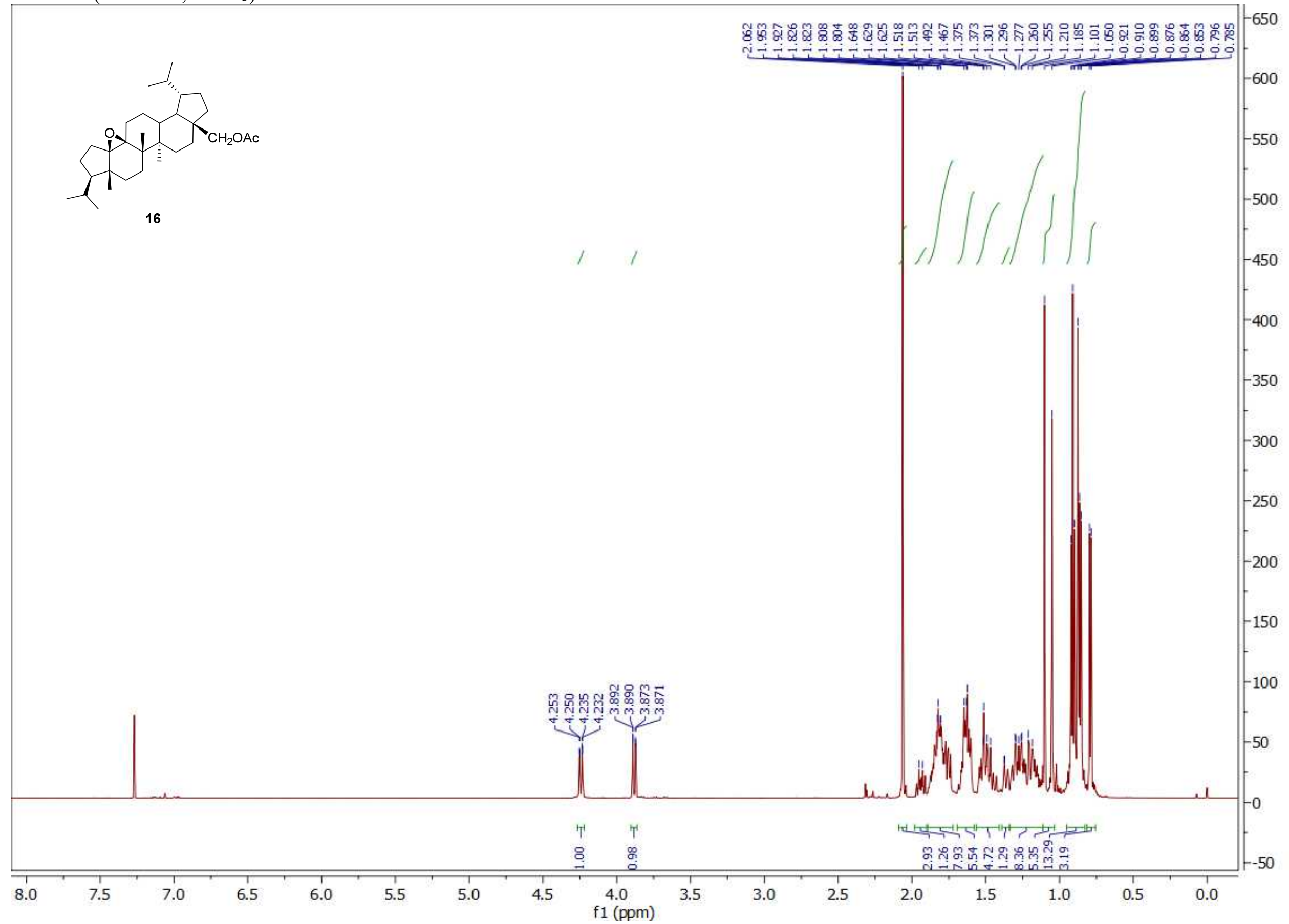




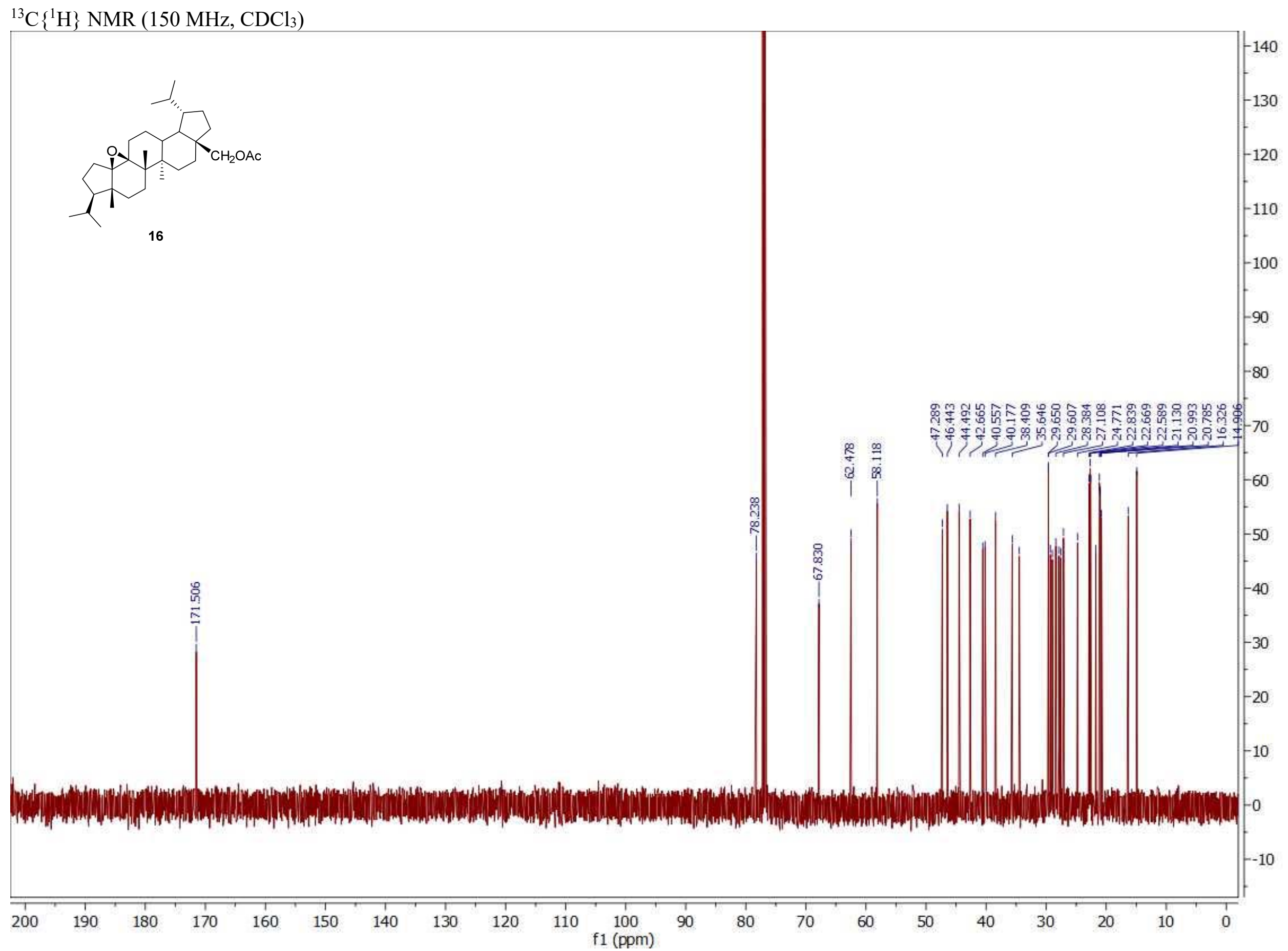


${ }^{1} \mathrm{H}$ NMR $\left(500 \mathrm{MHz}, \mathrm{CDCl}_{3}\right)$

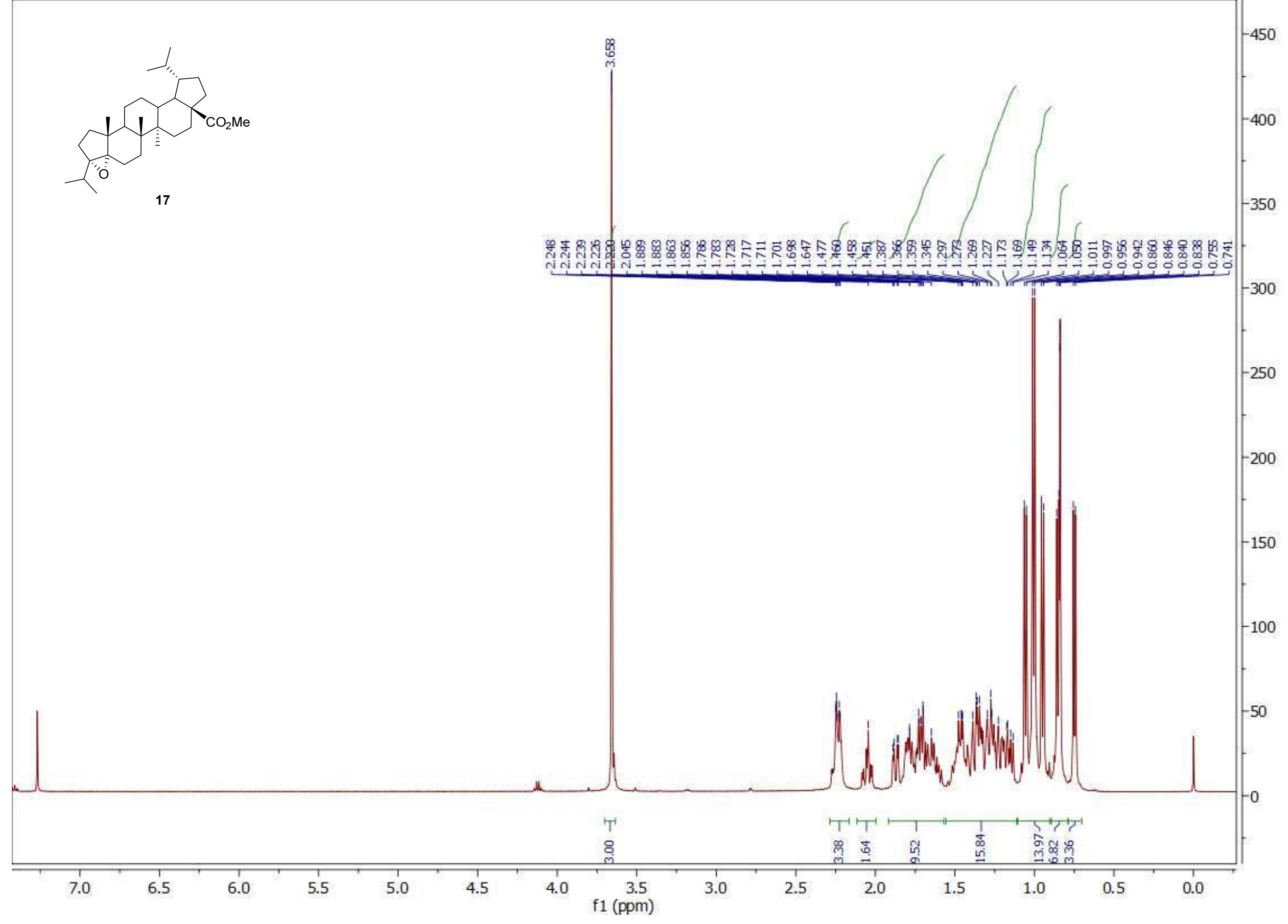


${ }^{13} \mathrm{C}\left\{{ }^{1} \mathrm{H}\right\}$ NMR $\left(125 \mathrm{MHz}, \mathrm{CDCl}_{3}\right)$

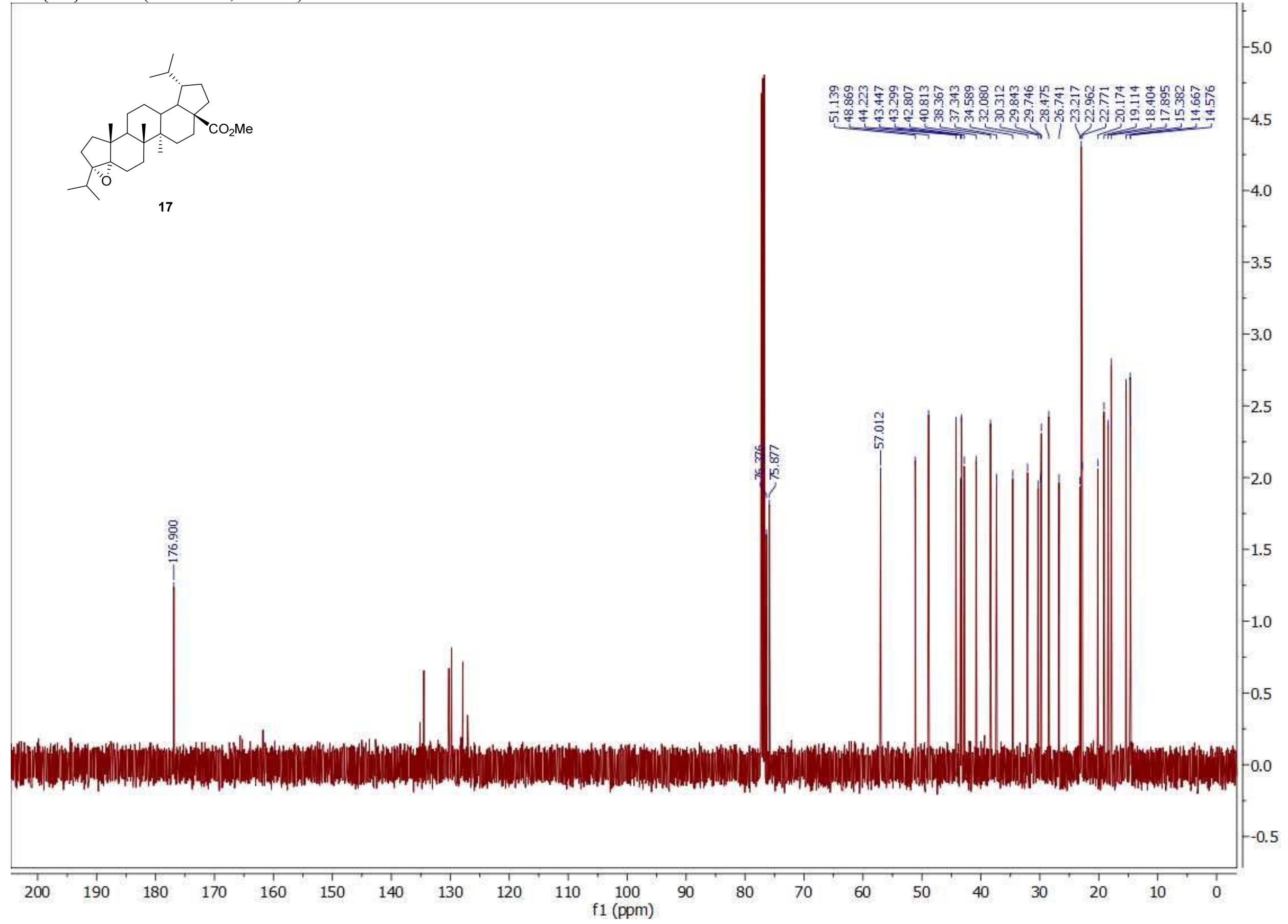


${ }^{1} \mathrm{H}$ NMR (500 MHz, $\left.\mathrm{CDCl}_{3}\right)$

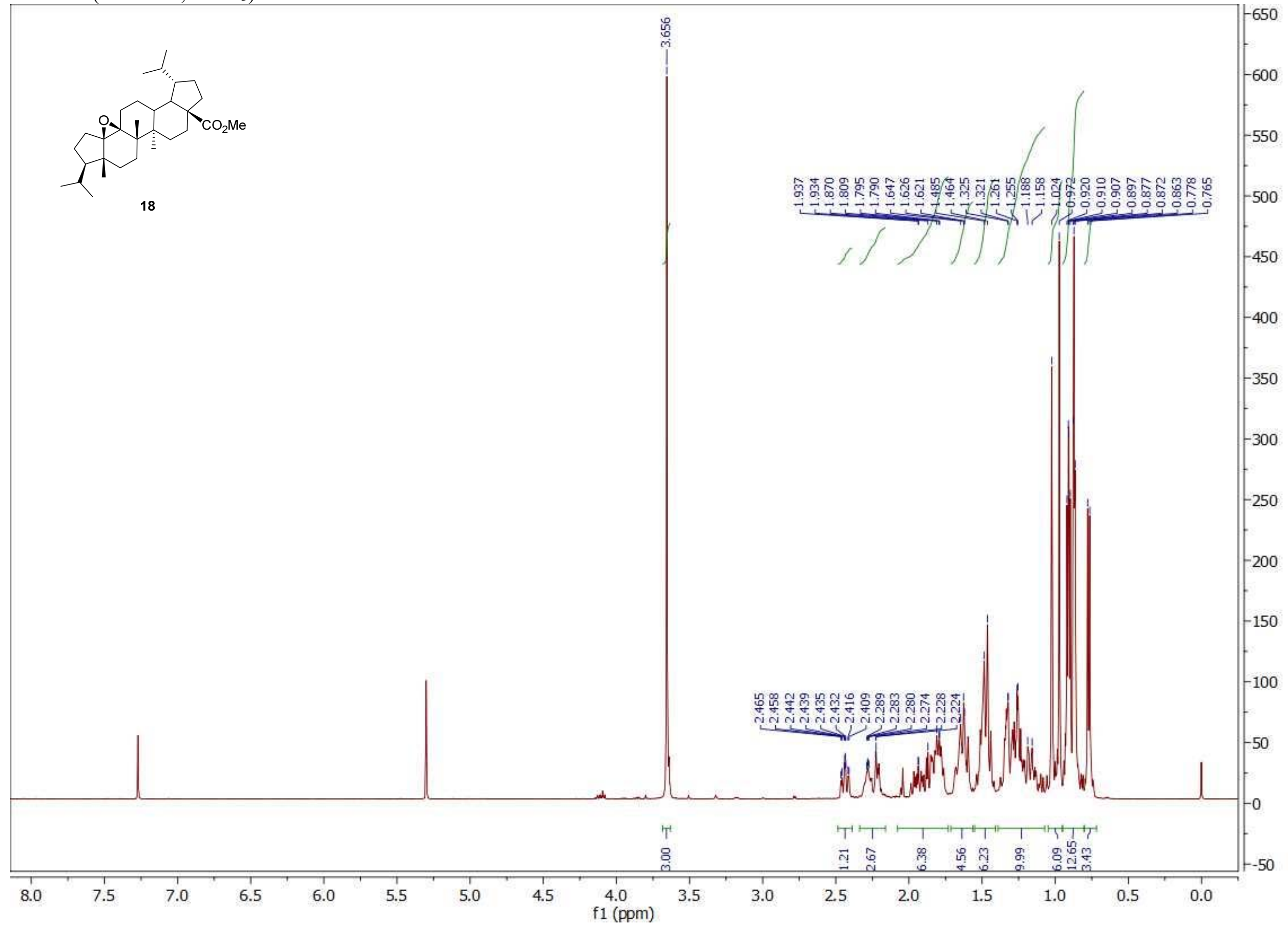


${ }^{13} \mathrm{C}\left\{{ }^{1} \mathrm{H}\right\}$ NMR $\left(125 \mathrm{MHz}, \mathrm{CDCl}_{3}\right)$

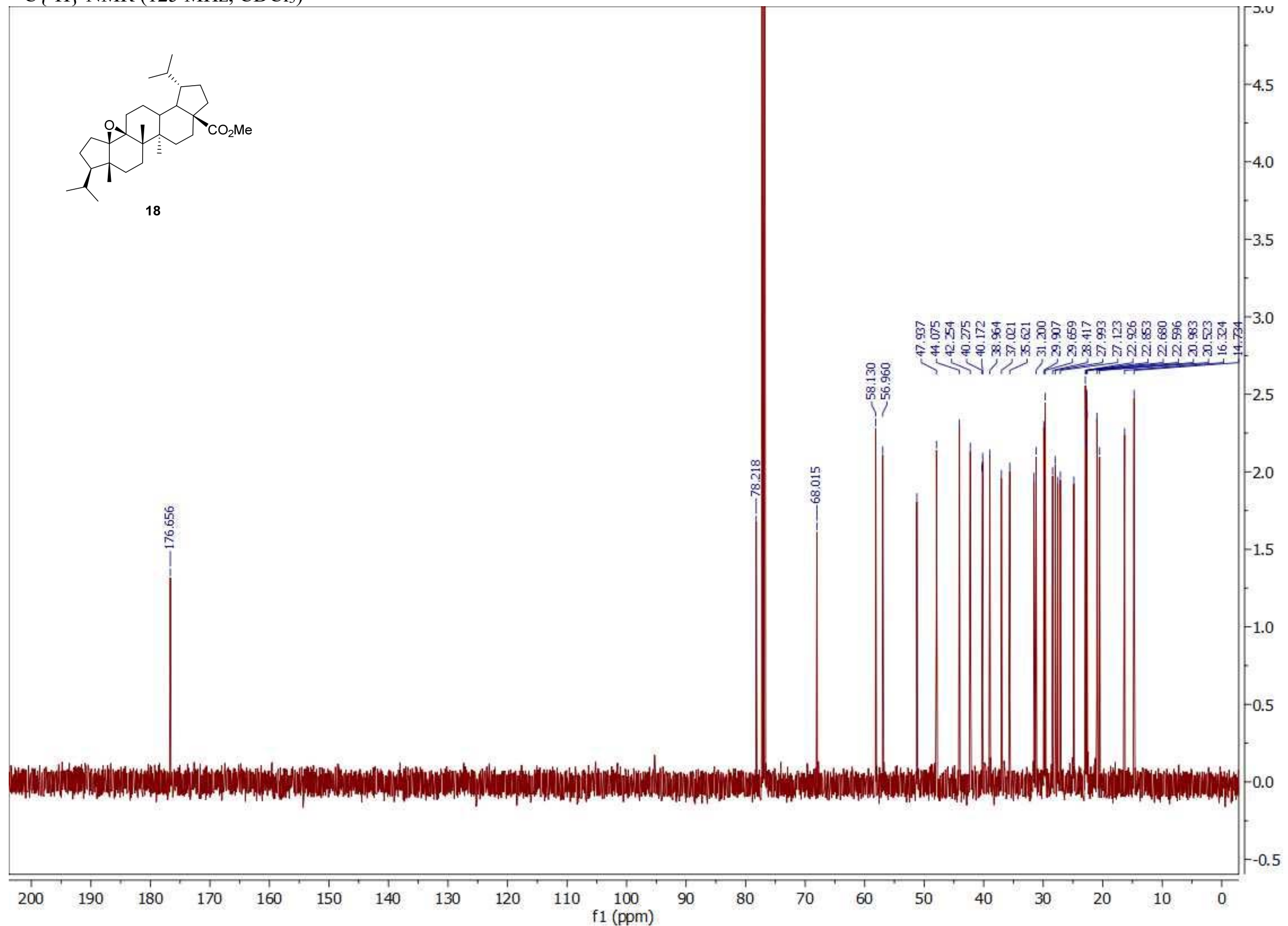


${ }^{1} \mathrm{H}$ NMR $\left(600 \mathrm{MHz}, \mathrm{CDCl}_{3}\right)$

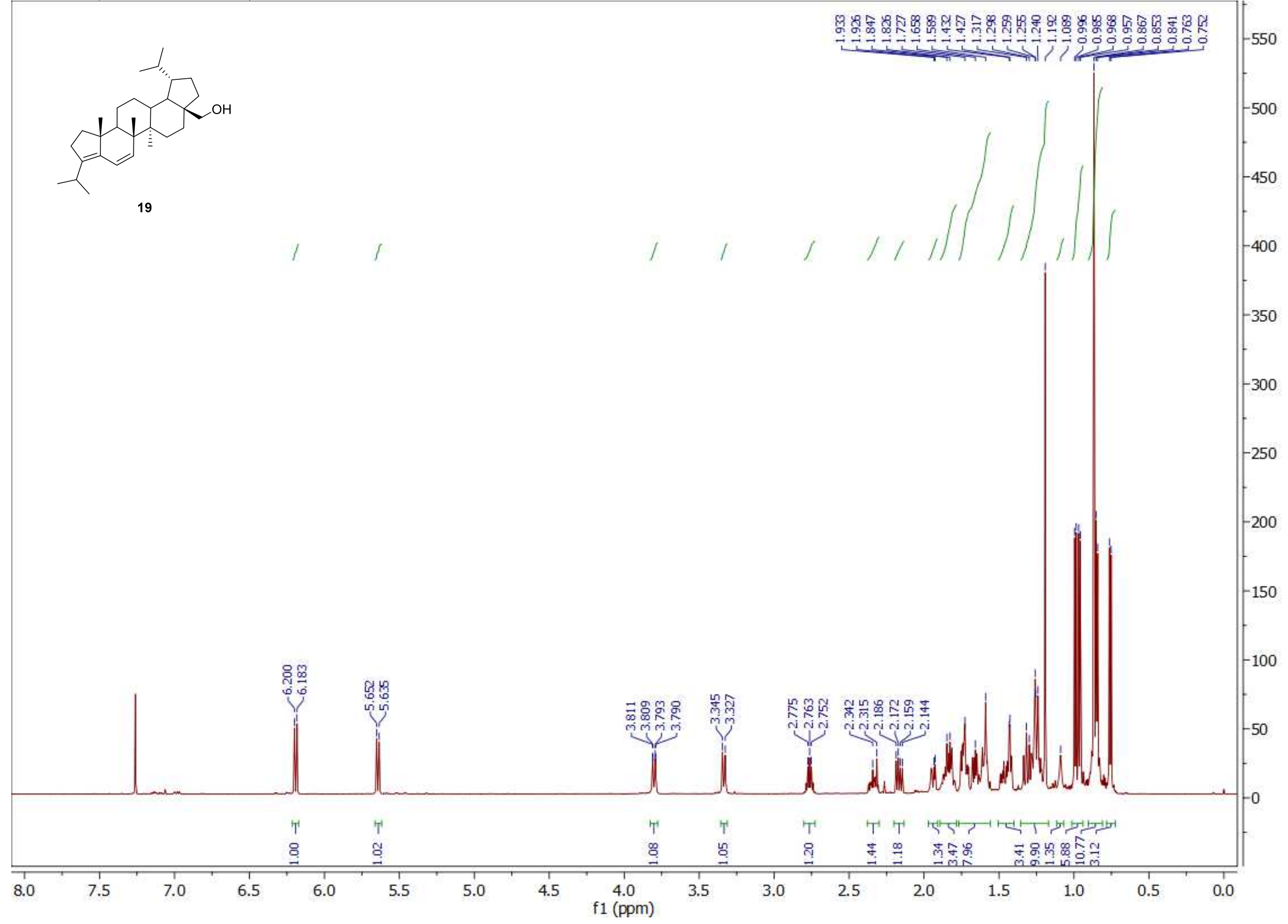


${ }^{13} \mathrm{C}\left\{{ }^{1} \mathrm{H}\right\}$ NMR $\left(150 \mathrm{MHz}, \mathrm{CDCl}_{3}\right)$
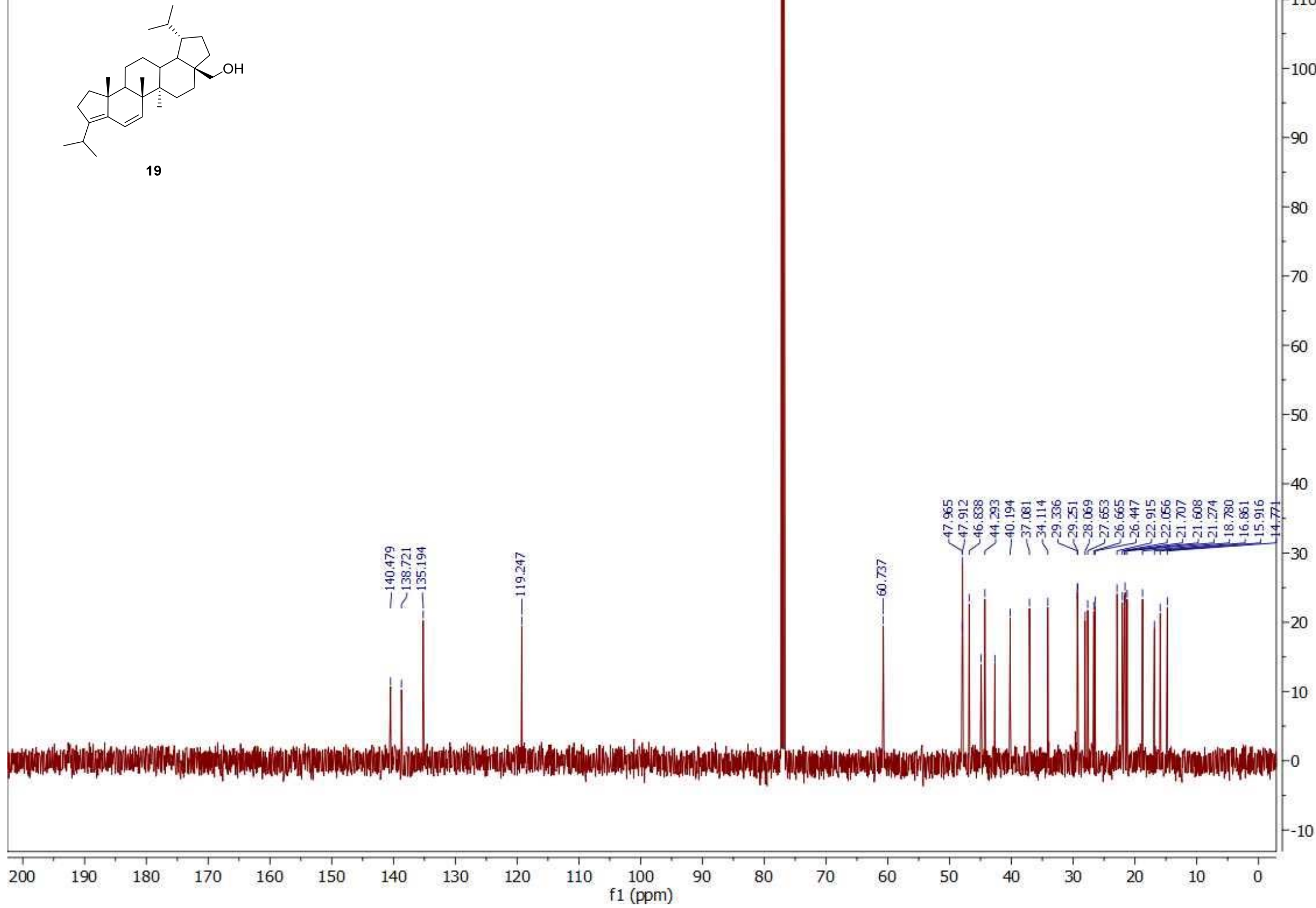
${ }^{1} \mathrm{H}$ NMR $\left(600 \mathrm{MHz}, \mathrm{CDCl}_{3}\right)$

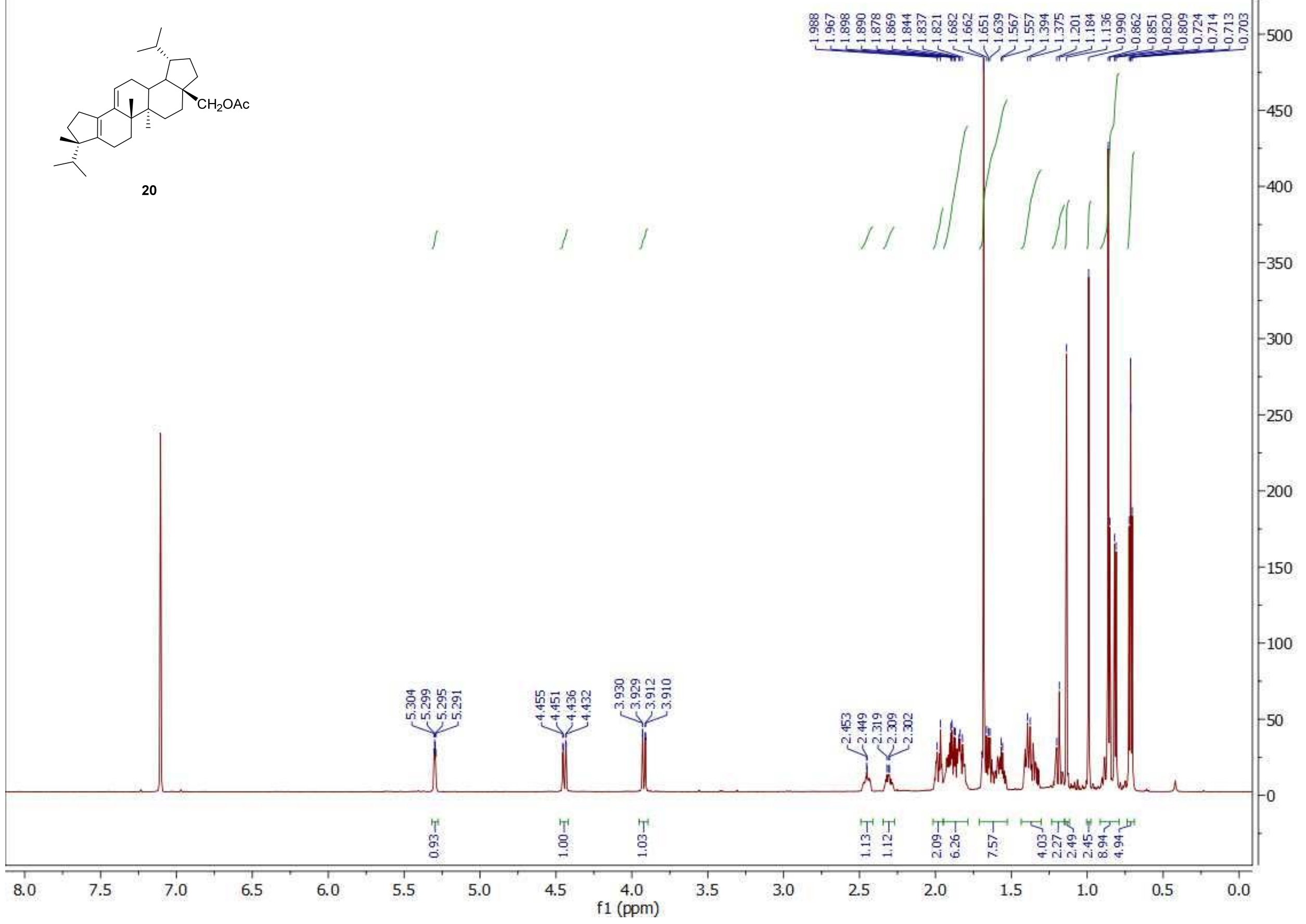




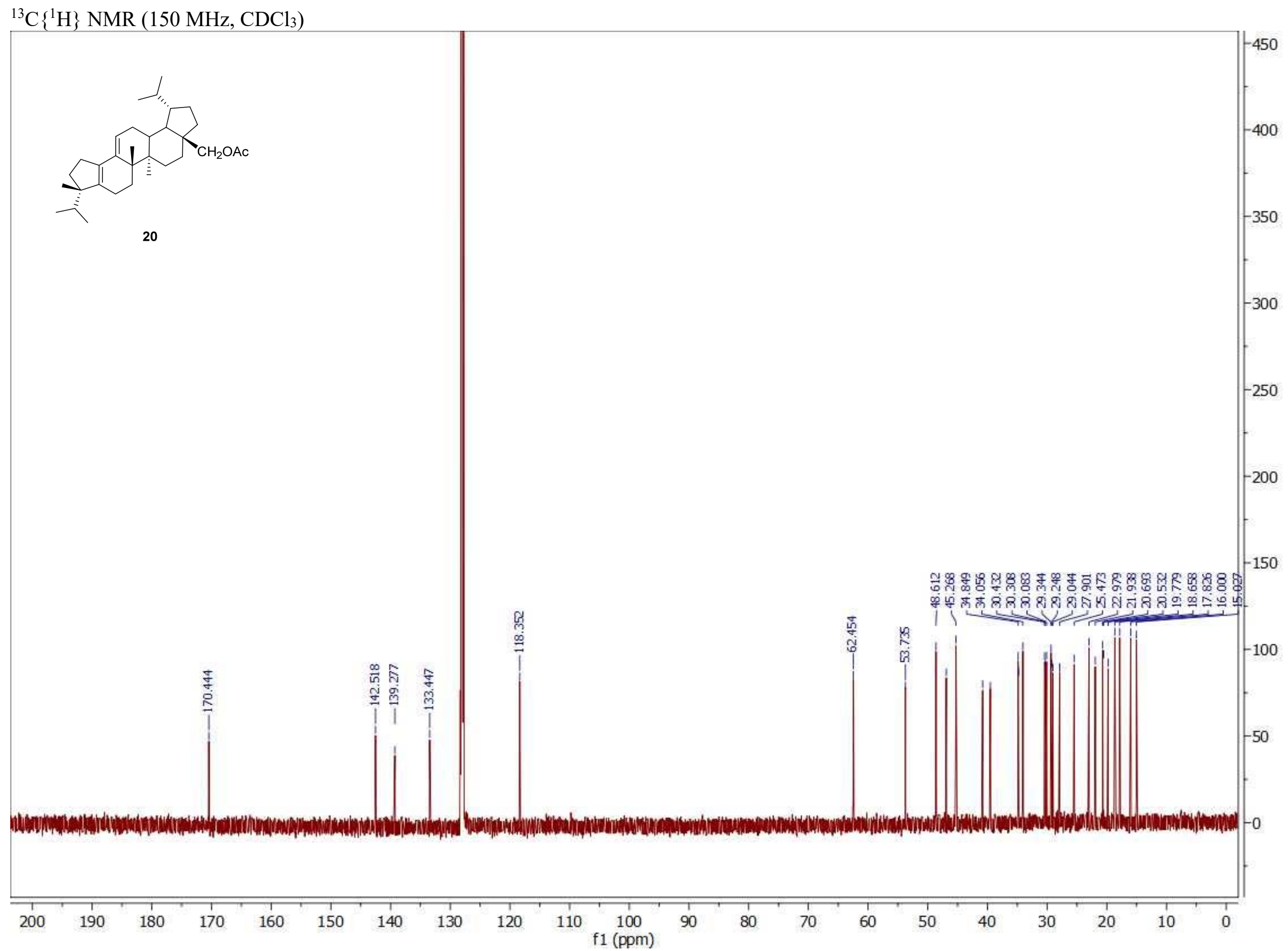


${ }^{1} \mathrm{H}$ NMR $\left(600 \mathrm{MHz}, \mathrm{CDCl}_{3}\right)$

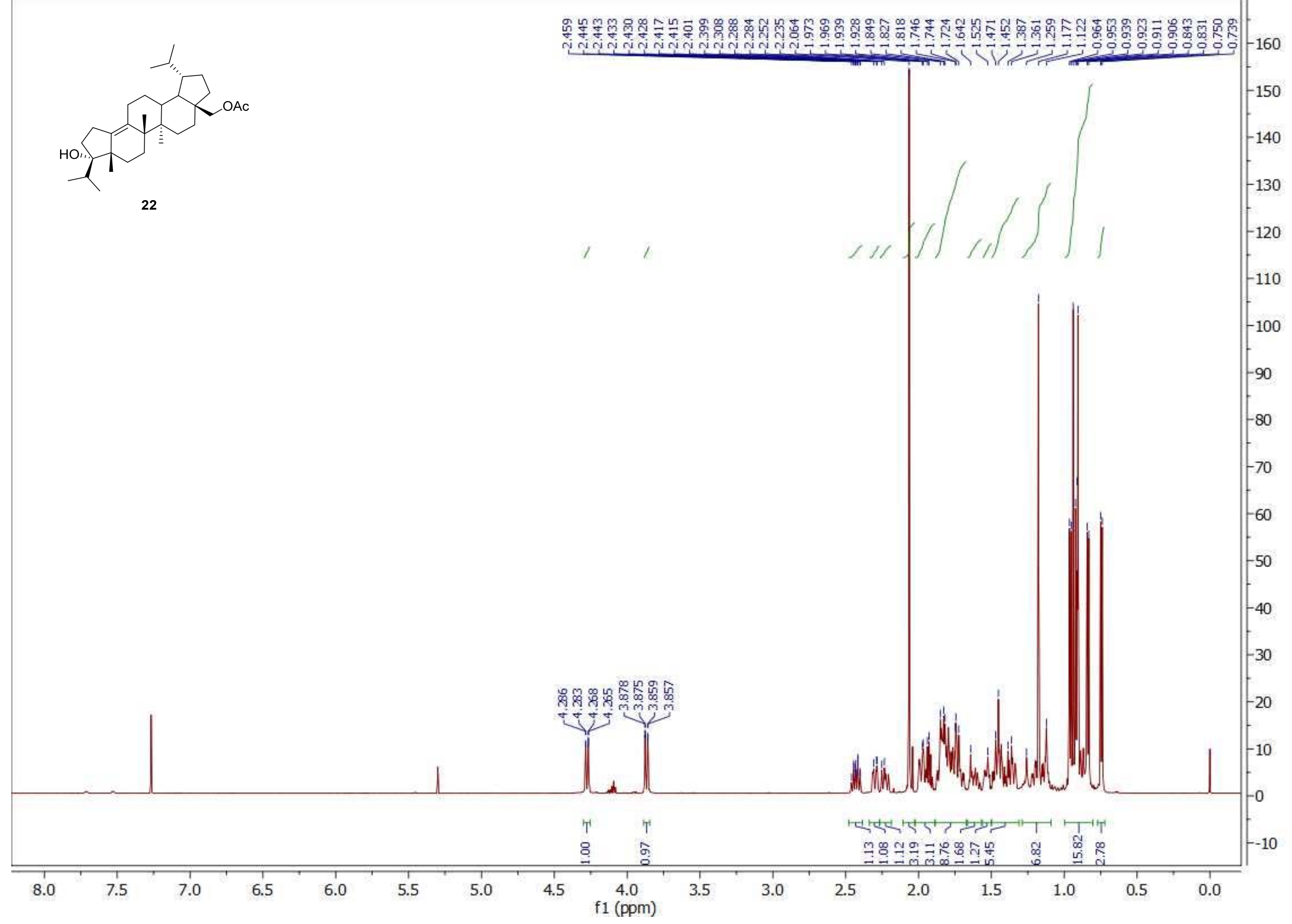


${ }^{13} \mathrm{C}\left\{{ }^{1} \mathrm{H}\right\}$ NMR $\left(150 \mathrm{MHz}, \mathrm{CDCl}_{3}\right)$

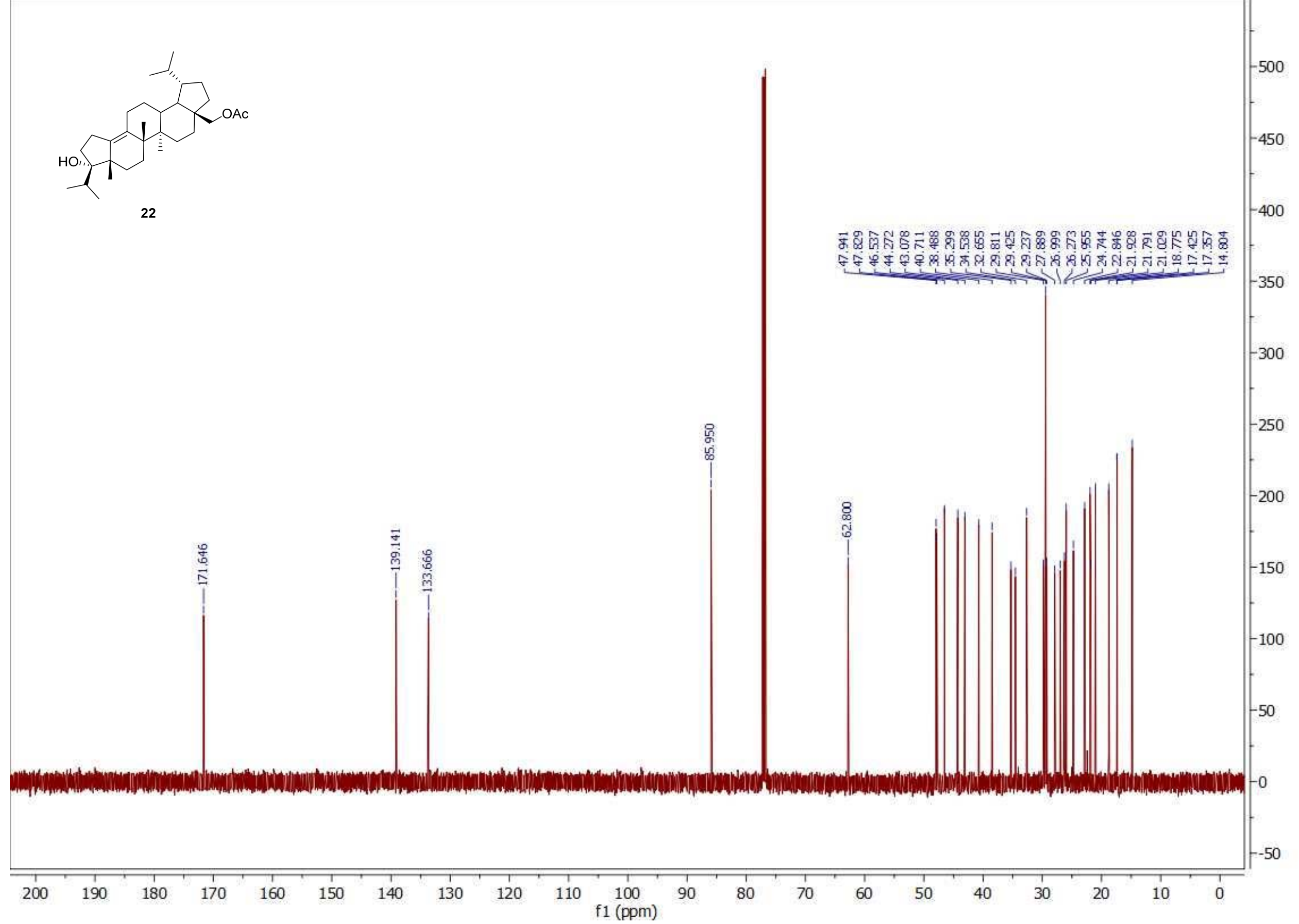


${ }^{1} \mathrm{H}$ NMR $\left(600 \mathrm{MHz}, \mathrm{CDCl}_{3}\right)$

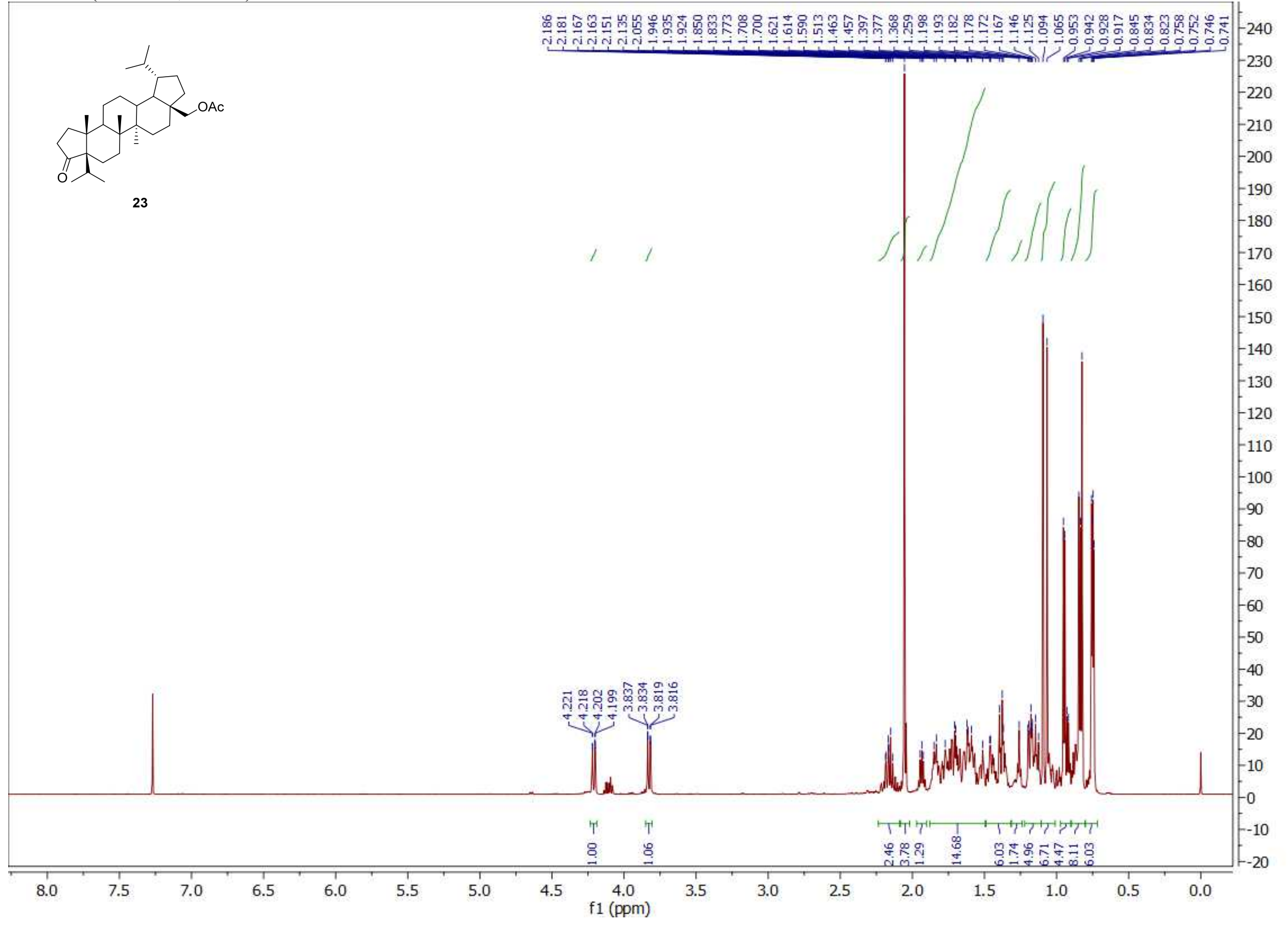


${ }^{13} \mathrm{C}\left\{{ }^{1} \mathrm{H}\right\} \mathrm{NMR}\left(150 \mathrm{MHz}, \mathrm{CDCl}_{3}\right)$

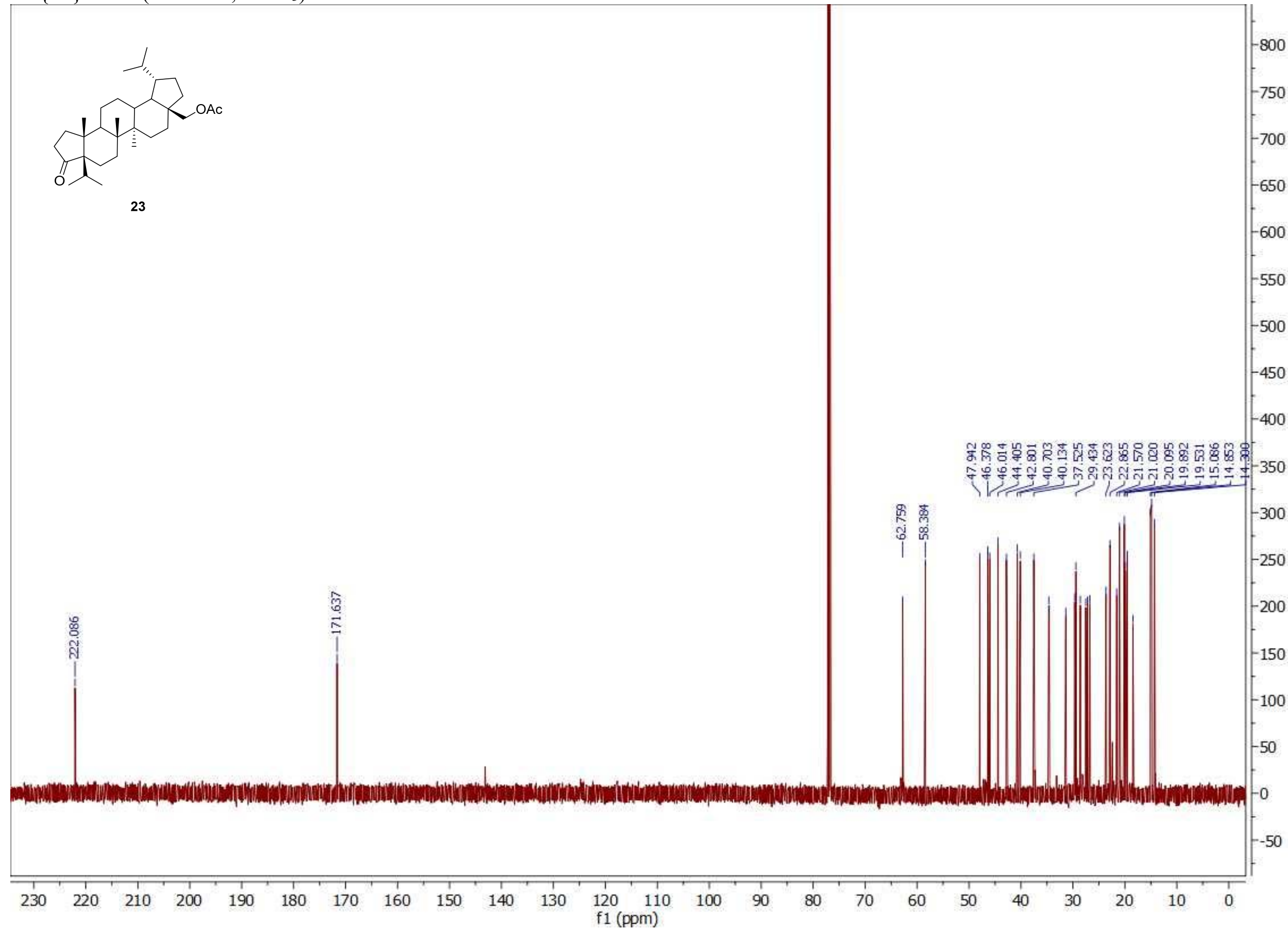


${ }^{1} \mathrm{H}$ NMR $\left(600 \mathrm{MHz}, \mathrm{CDCl}_{3}\right)$

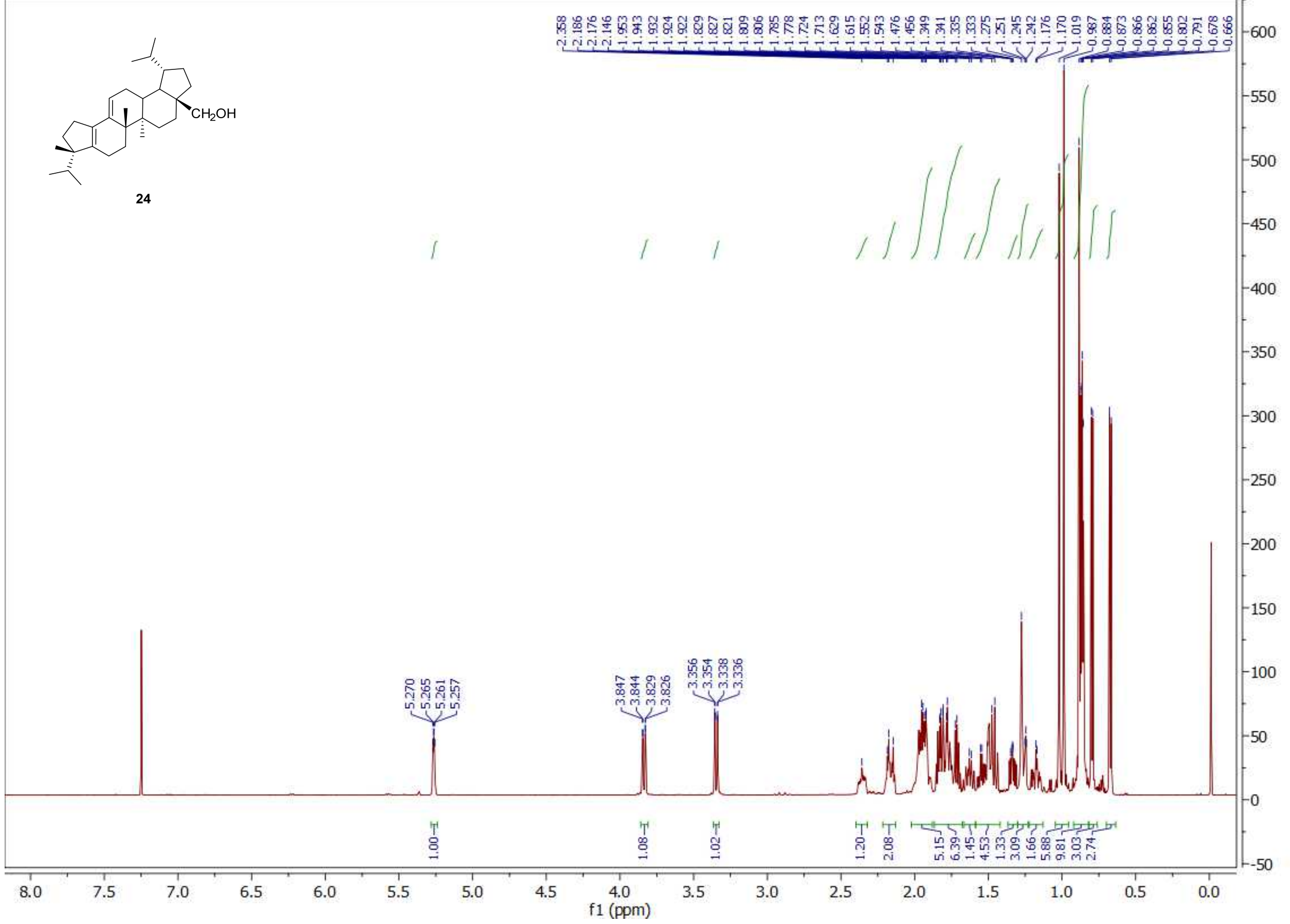


${ }^{13} \mathrm{C}\left\{{ }^{1} \mathrm{H}\right\} \mathrm{NMR}\left(150 \mathrm{MHz}, \mathrm{CDCl}_{3}\right)$

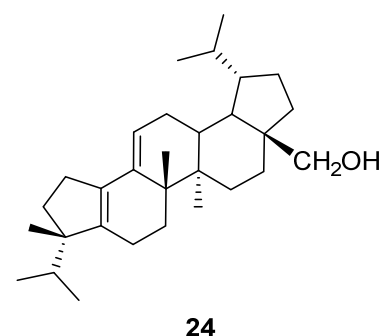


${ }^{1} \mathrm{H}$ NMR $\left(600 \mathrm{MHz}, \mathrm{CDCl}_{3}\right)$

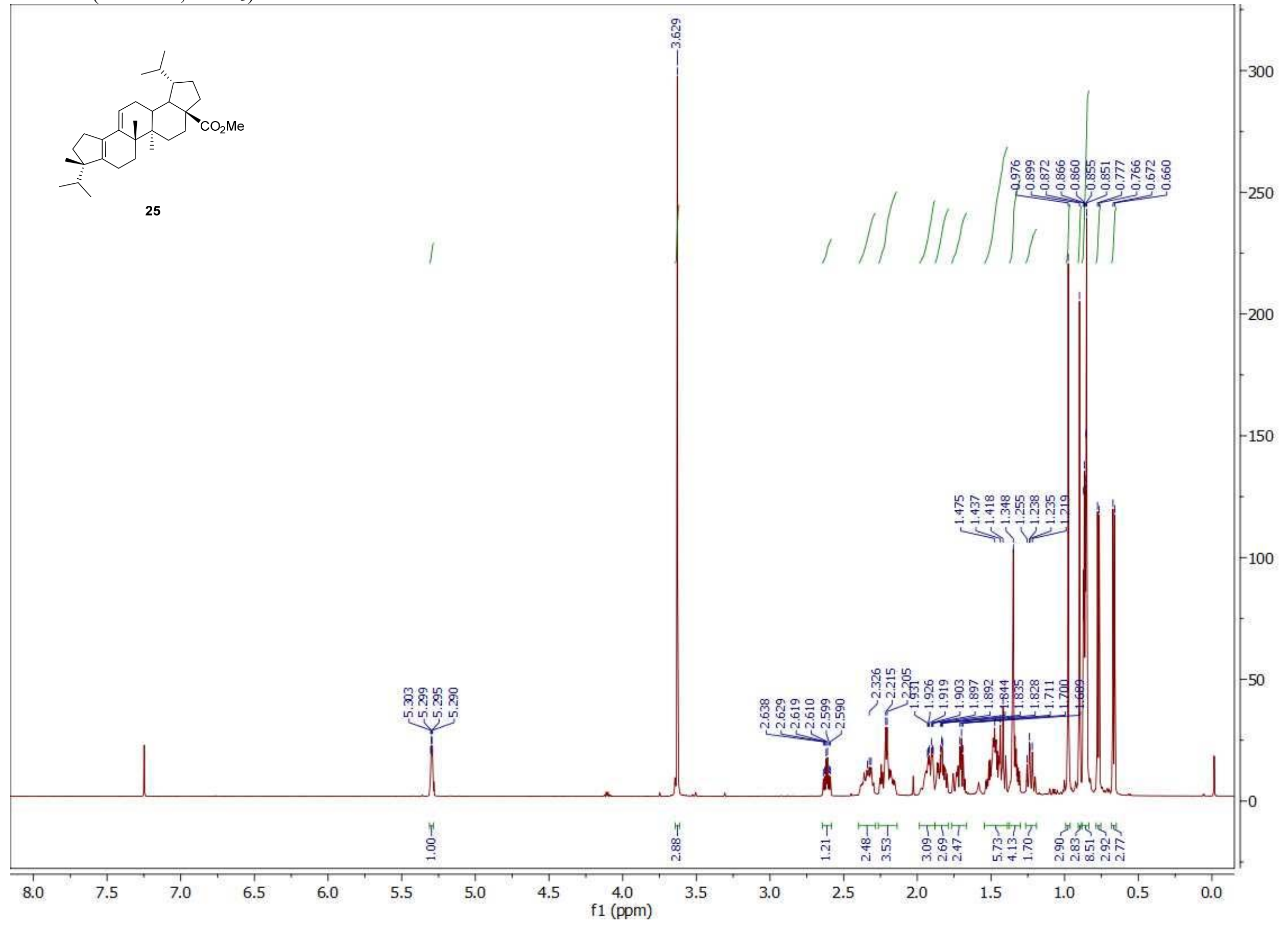


${ }^{13} \mathrm{C}\left\{{ }^{1} \mathrm{H}\right\} \mathrm{NMR}\left(150 \mathrm{MHz}, \mathrm{CDCl}_{3}\right)$

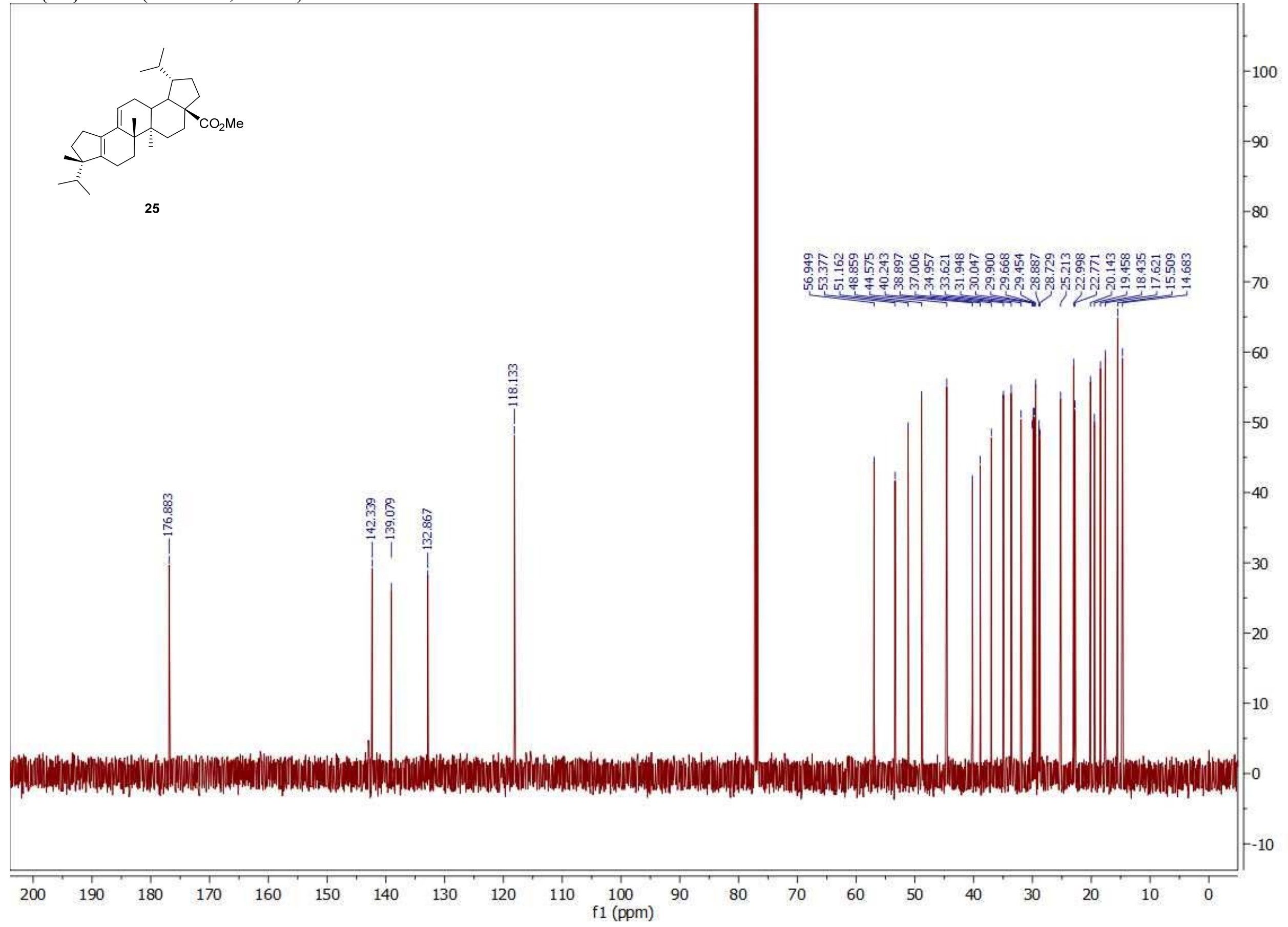


${ }^{1} \mathrm{H}$ NMR $\left(600 \mathrm{MHz}, \mathrm{CDCl}_{3}\right)$

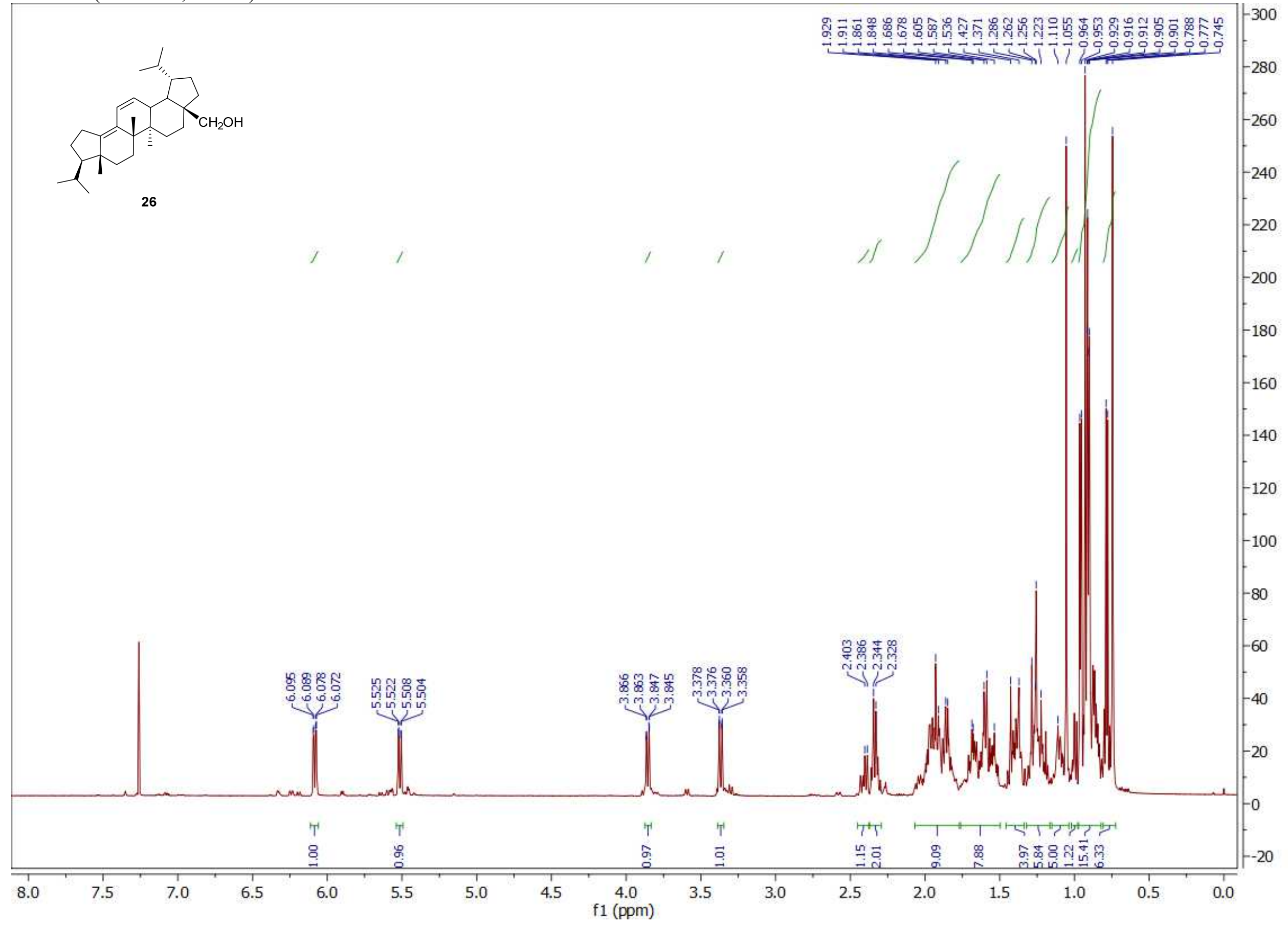


${ }^{13} \mathrm{C}\left\{{ }^{1} \mathrm{H}\right\} \mathrm{NMR}\left(150 \mathrm{MHz}, \mathrm{CDCl}_{3}\right)$

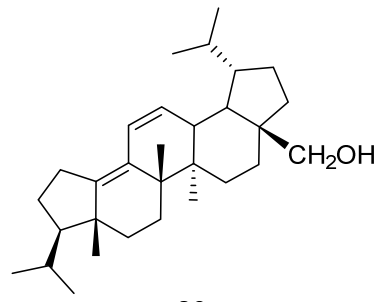

26

$-250$

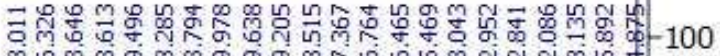

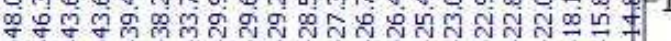
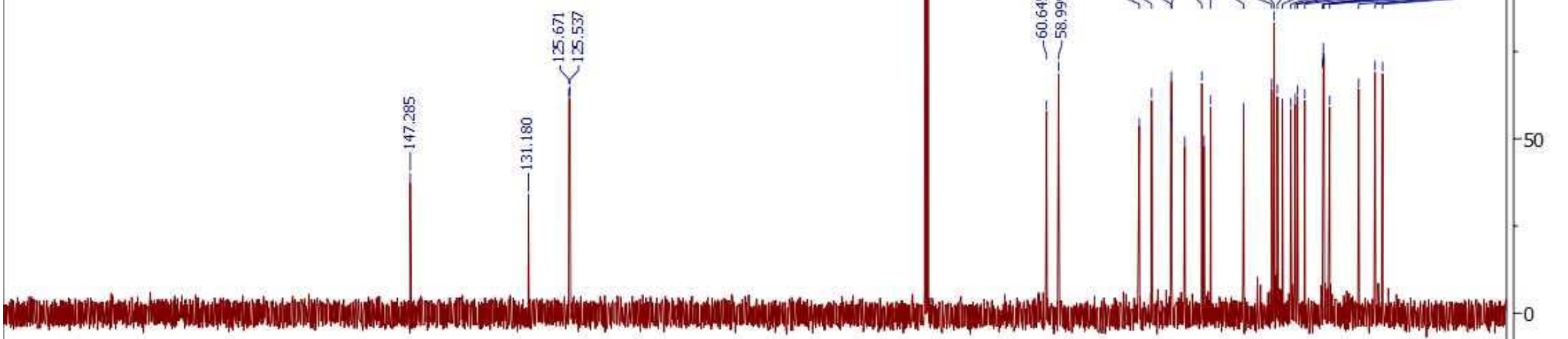
${ }^{1} \mathrm{H}$ NMR $\left(500 \mathrm{MHz}, \mathrm{CDCl}_{3}\right)$

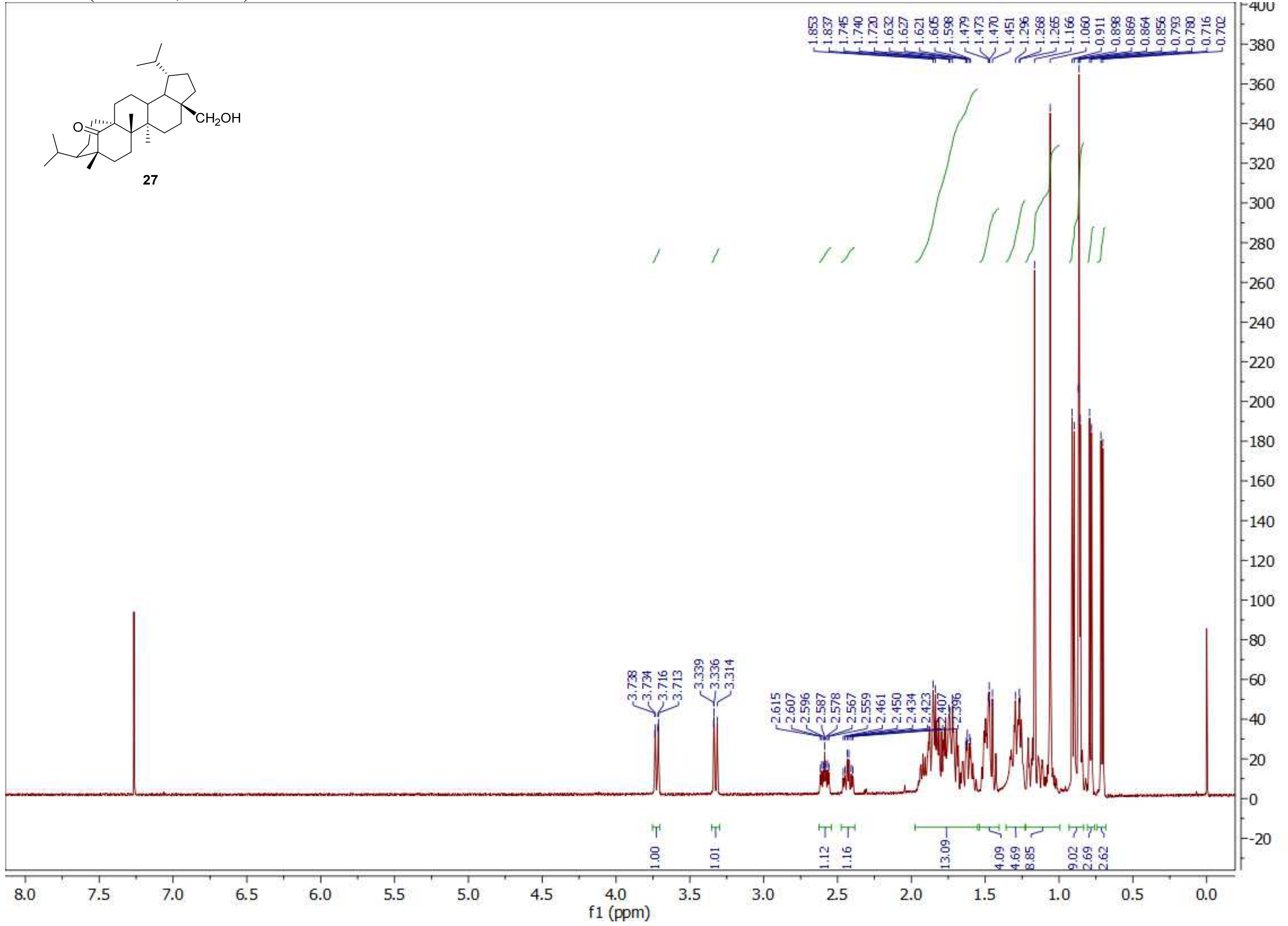




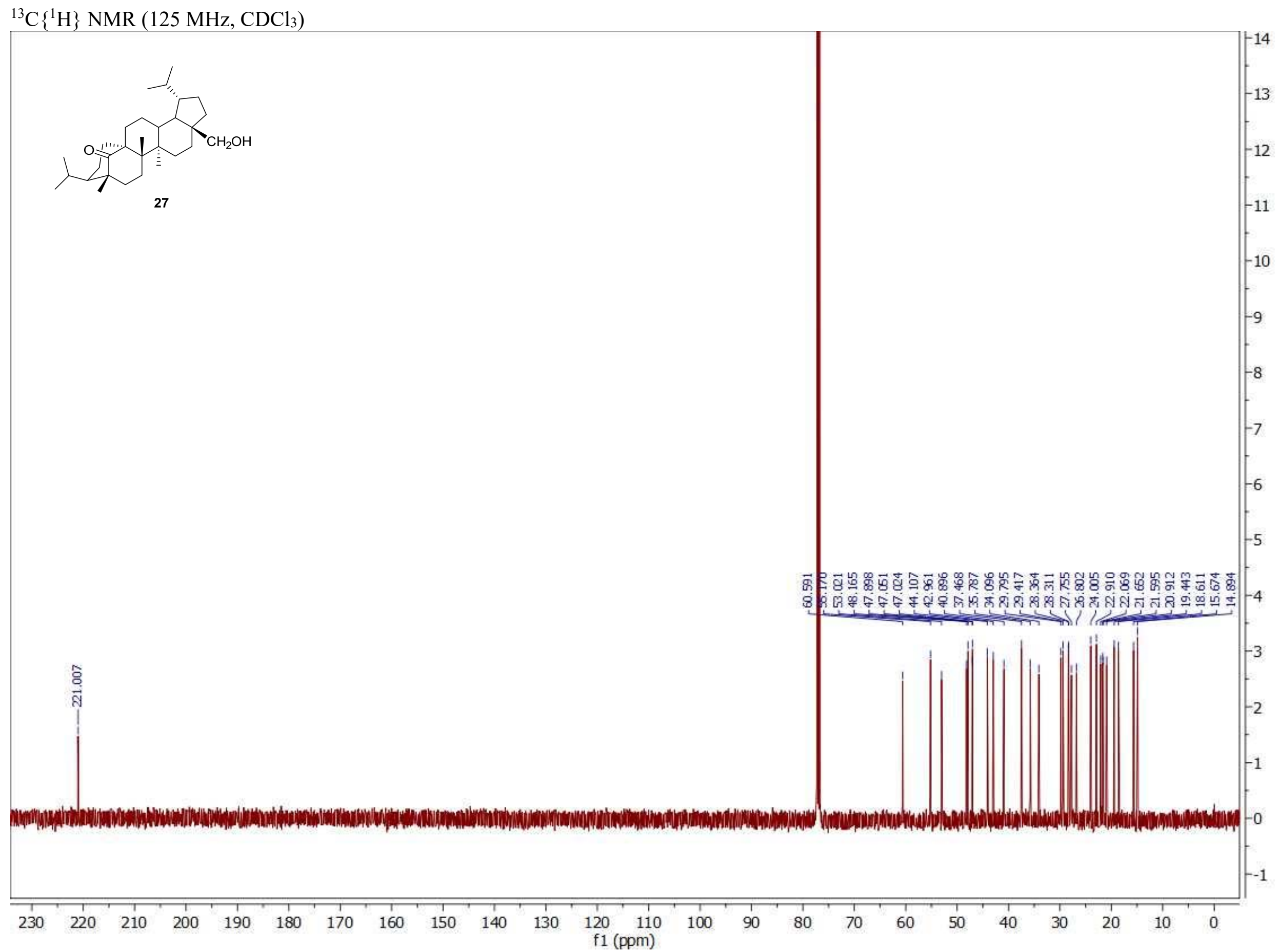


${ }^{1} \mathrm{H}$ NMR $\left(600 \mathrm{MHz}, \mathrm{CDCl}_{3}\right)$

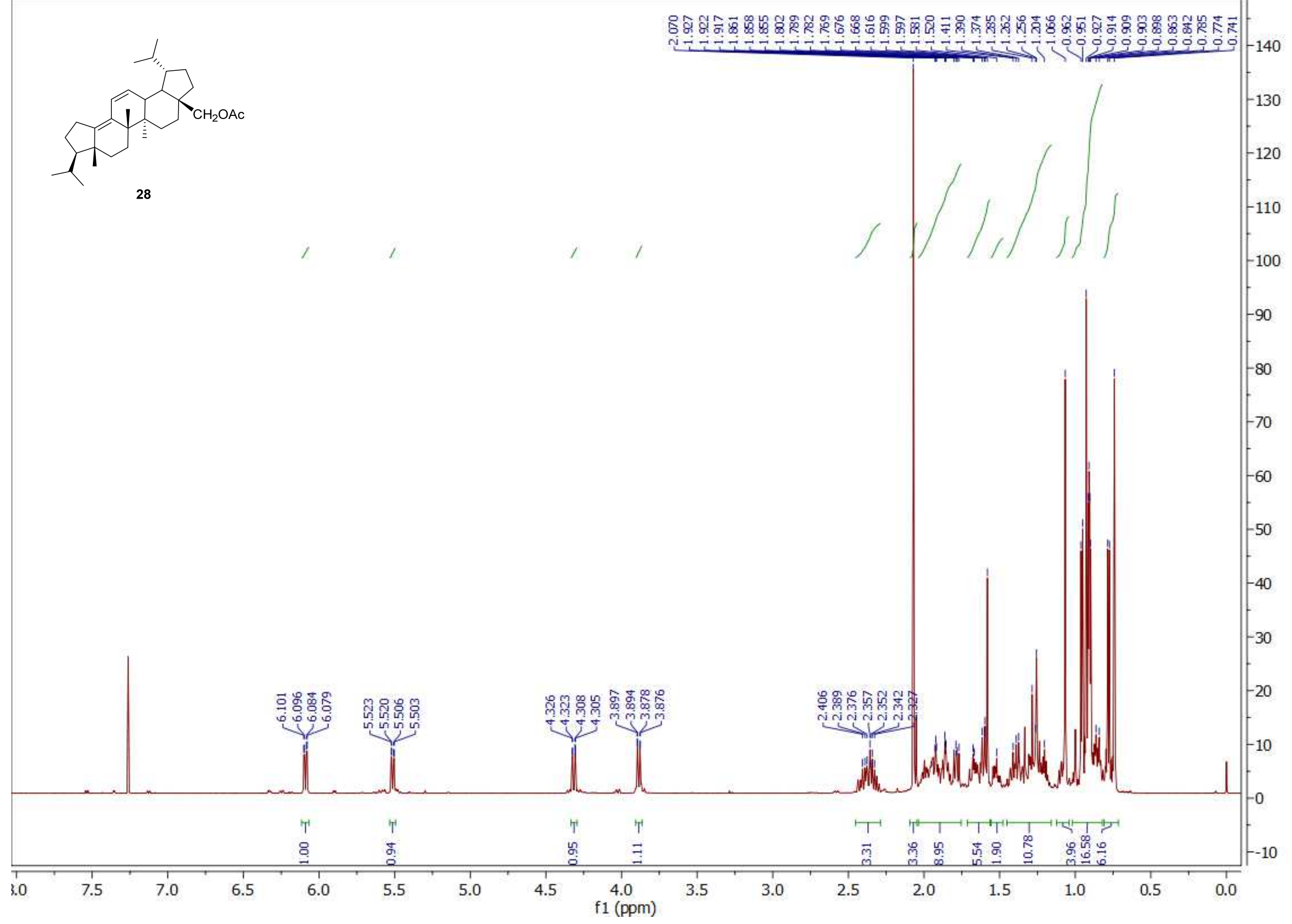


${ }^{13} \mathrm{C}\left\{{ }^{1} \mathrm{H}\right\}$ NMR $\left(150 \mathrm{MHz}, \mathrm{CDCl}_{3}\right)$

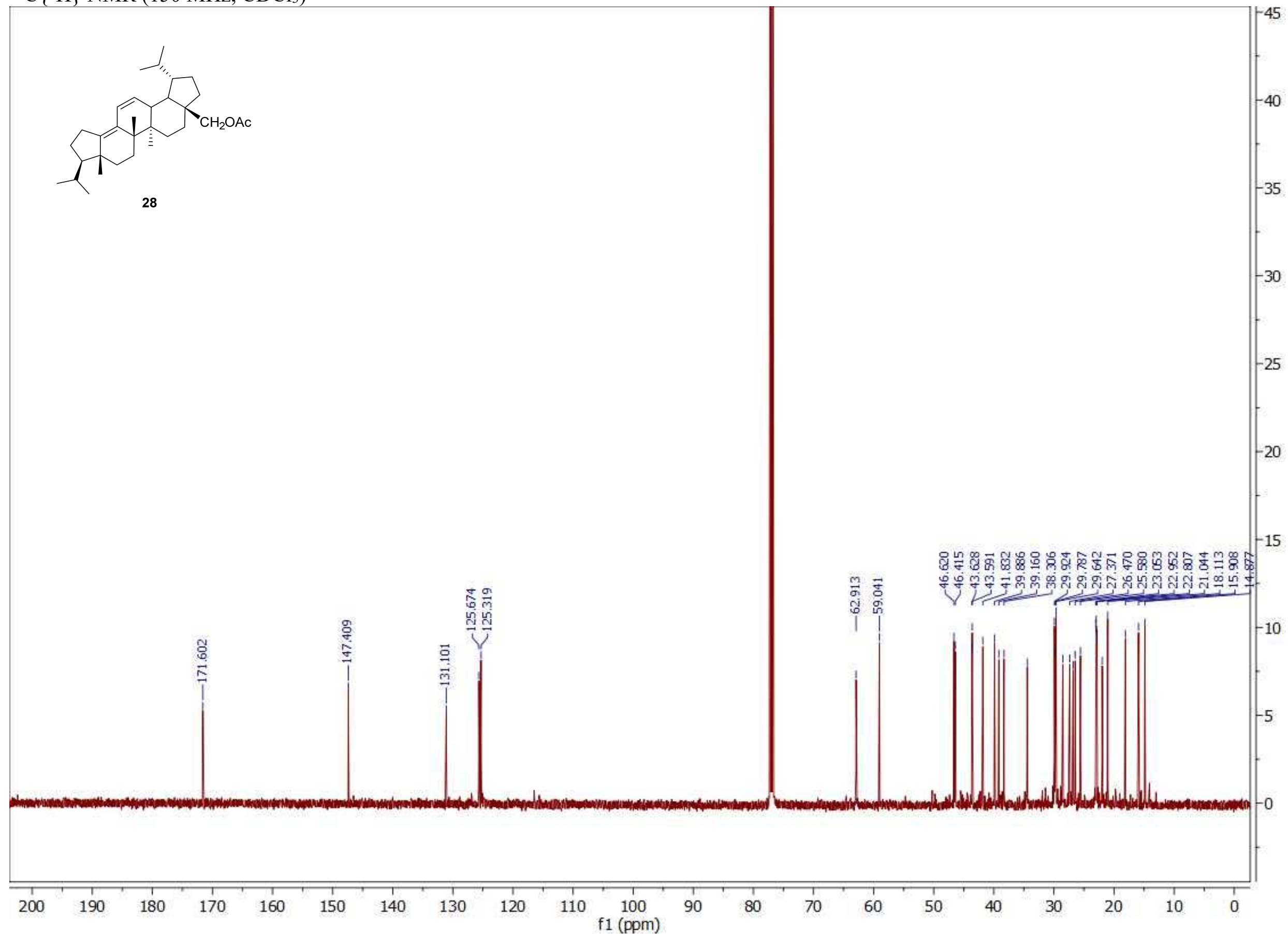


${ }^{1} \mathrm{H}$ NMR $\left(600 \mathrm{MHz}, \mathrm{CDCl}_{3}\right)$

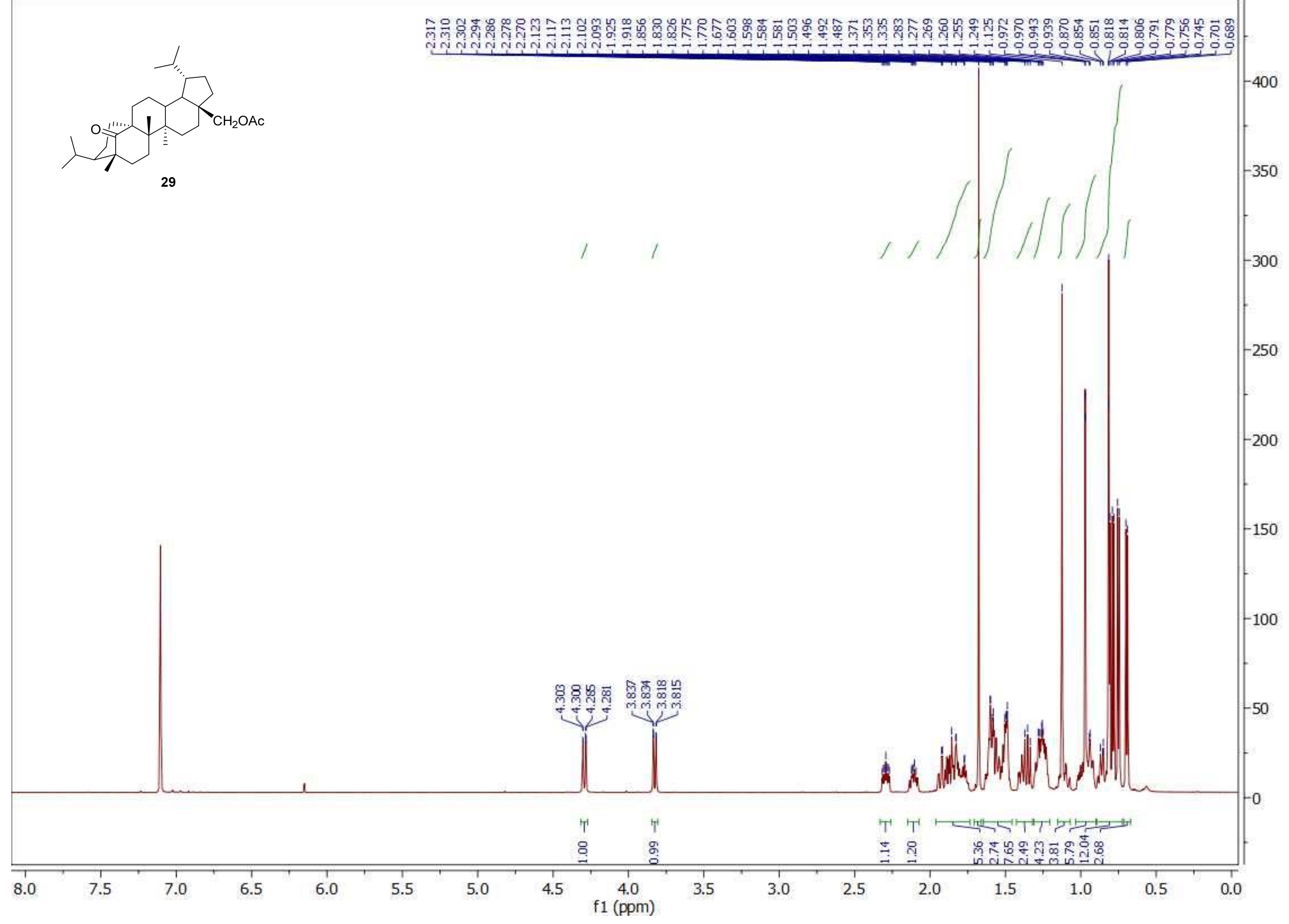




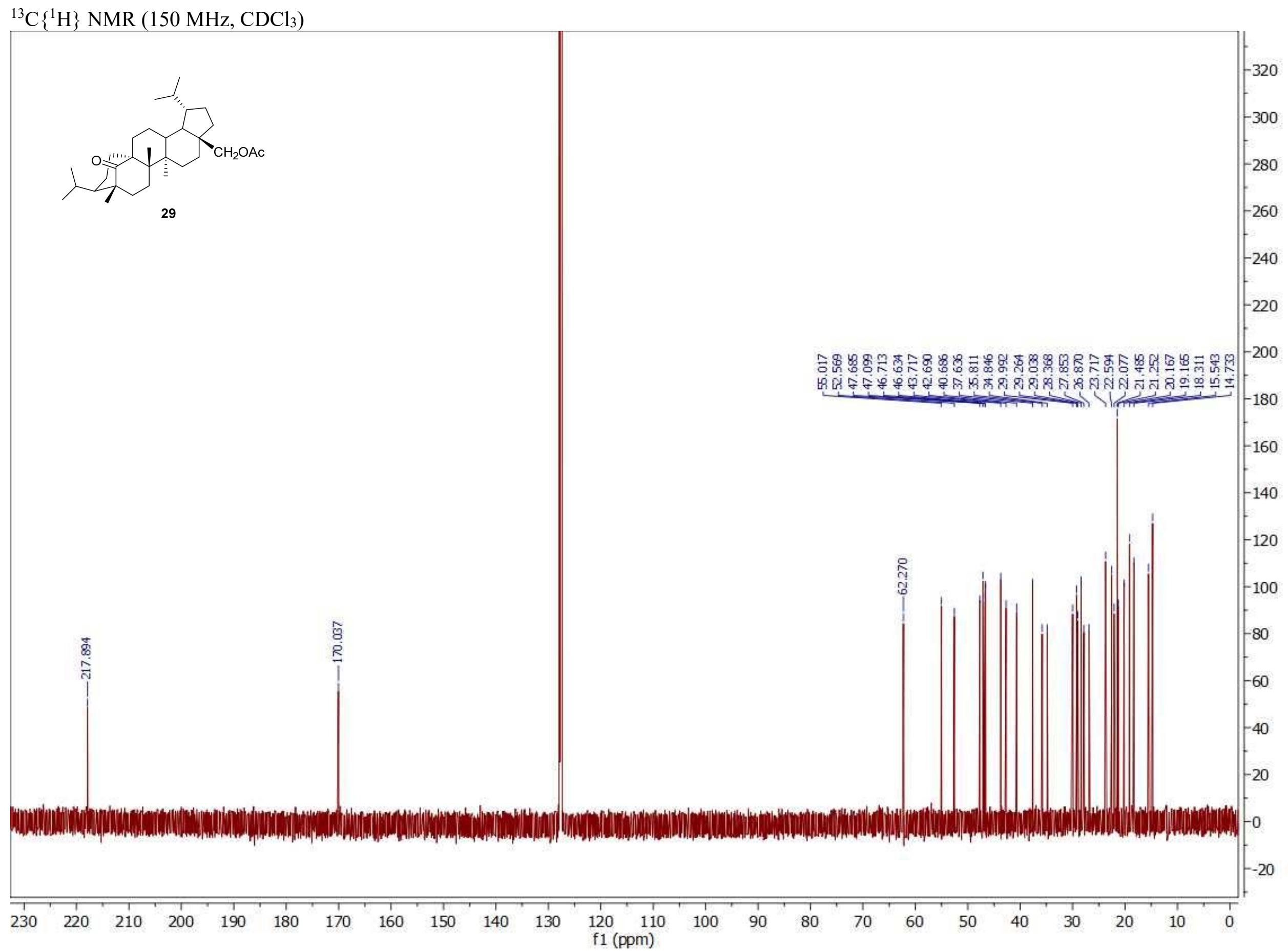


${ }^{1} \mathrm{H}$ NMR $\left(600 \mathrm{MHz}, \mathrm{CDCl}_{3}\right)$

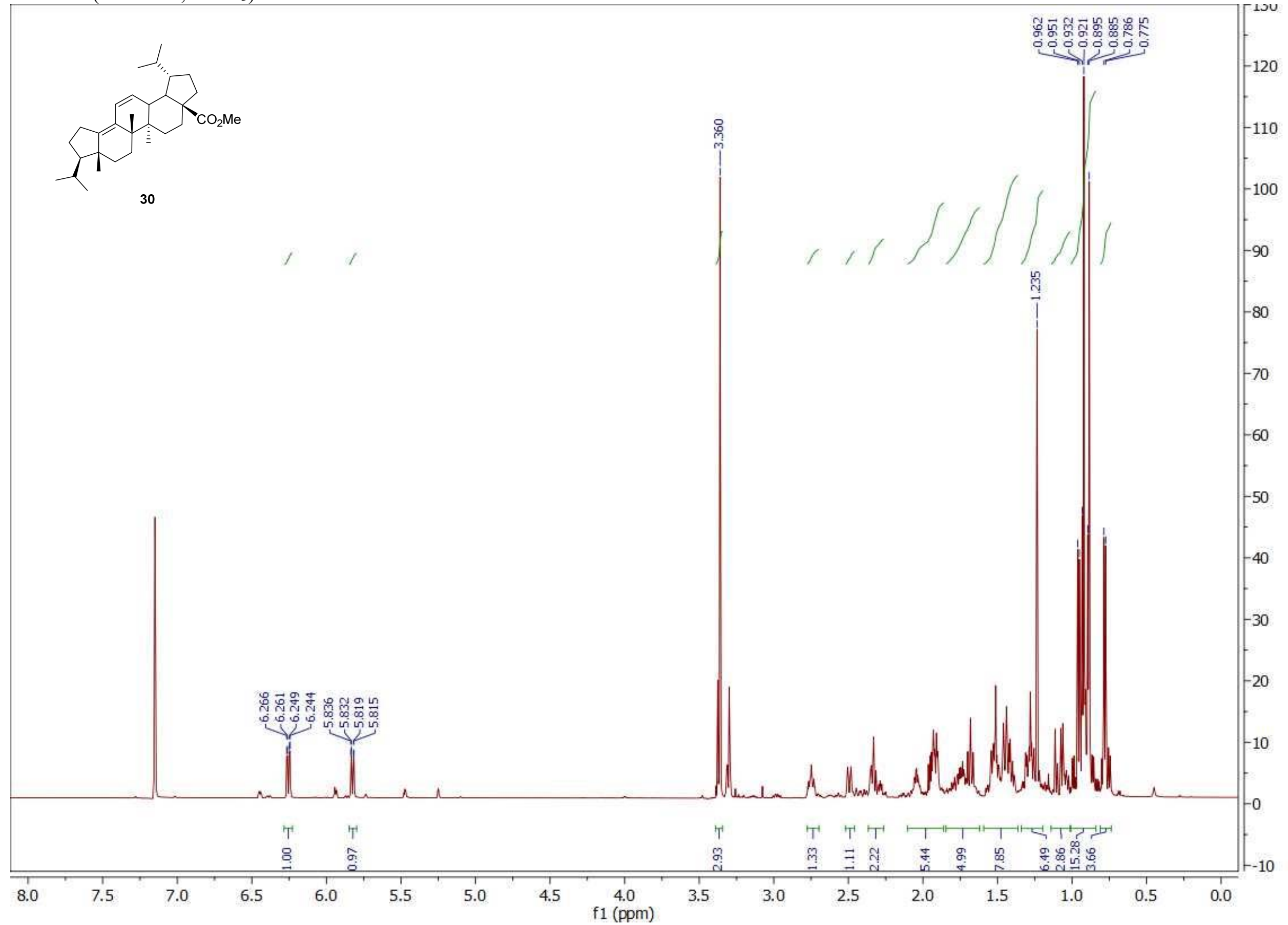




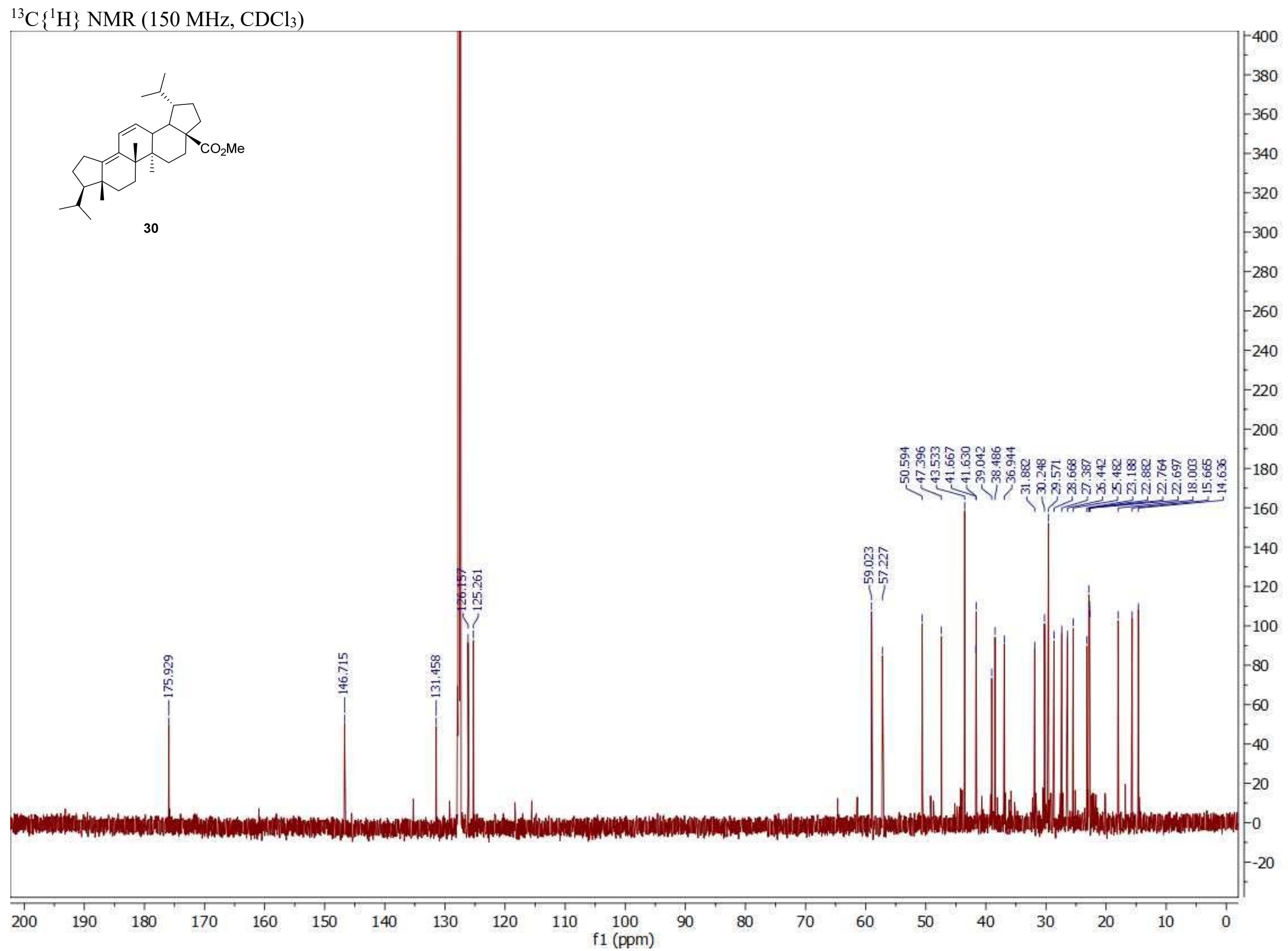


${ }^{1} \mathrm{H}$ NMR (600 MHz, $\mathrm{CDCl}_{3}$ )

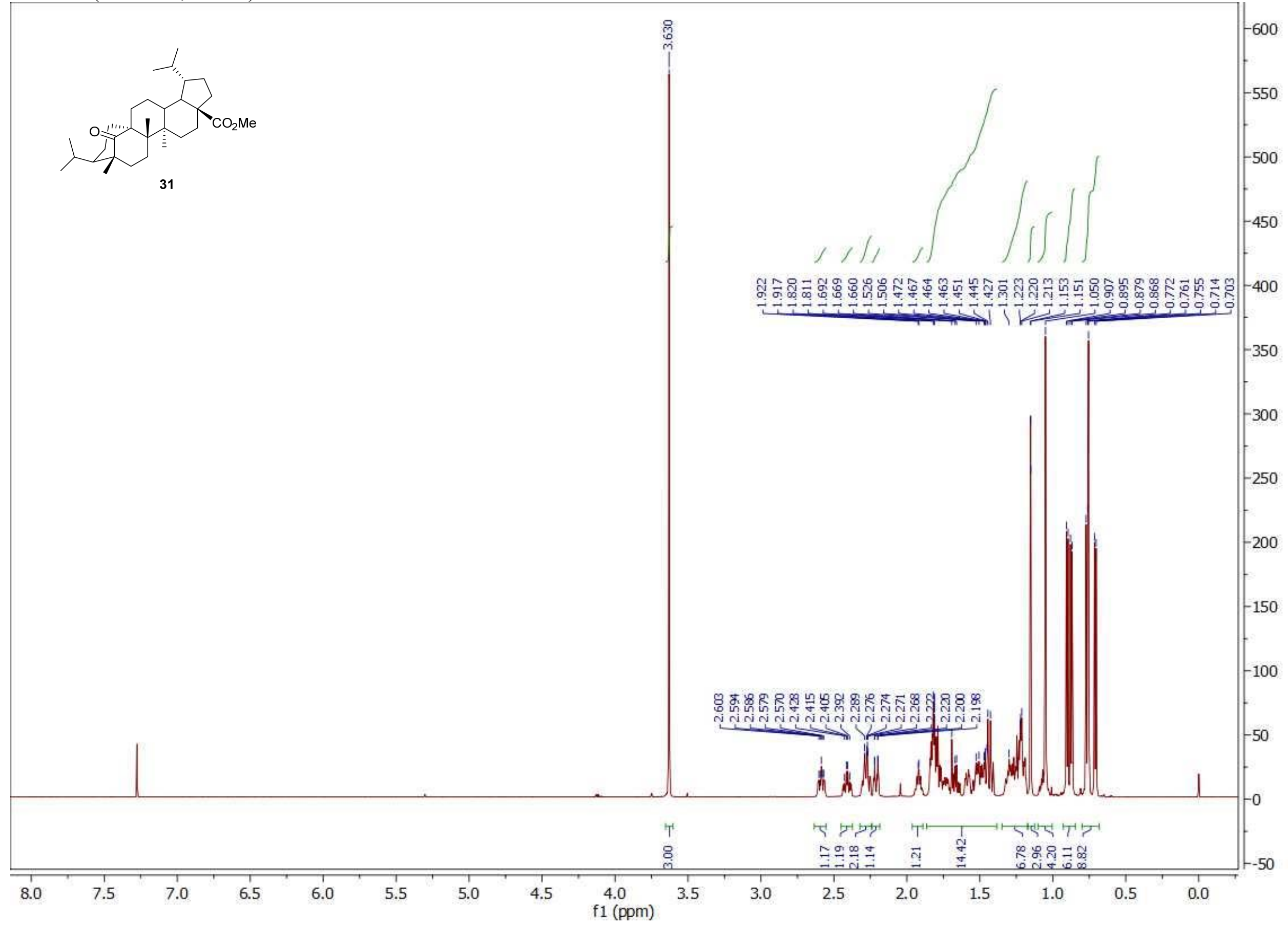


${ }^{13} \mathrm{C}\left\{{ }^{1} \mathrm{H}\right\}$ NMR $\left(150 \mathrm{MHz}, \mathrm{CDCl}_{3}\right)$

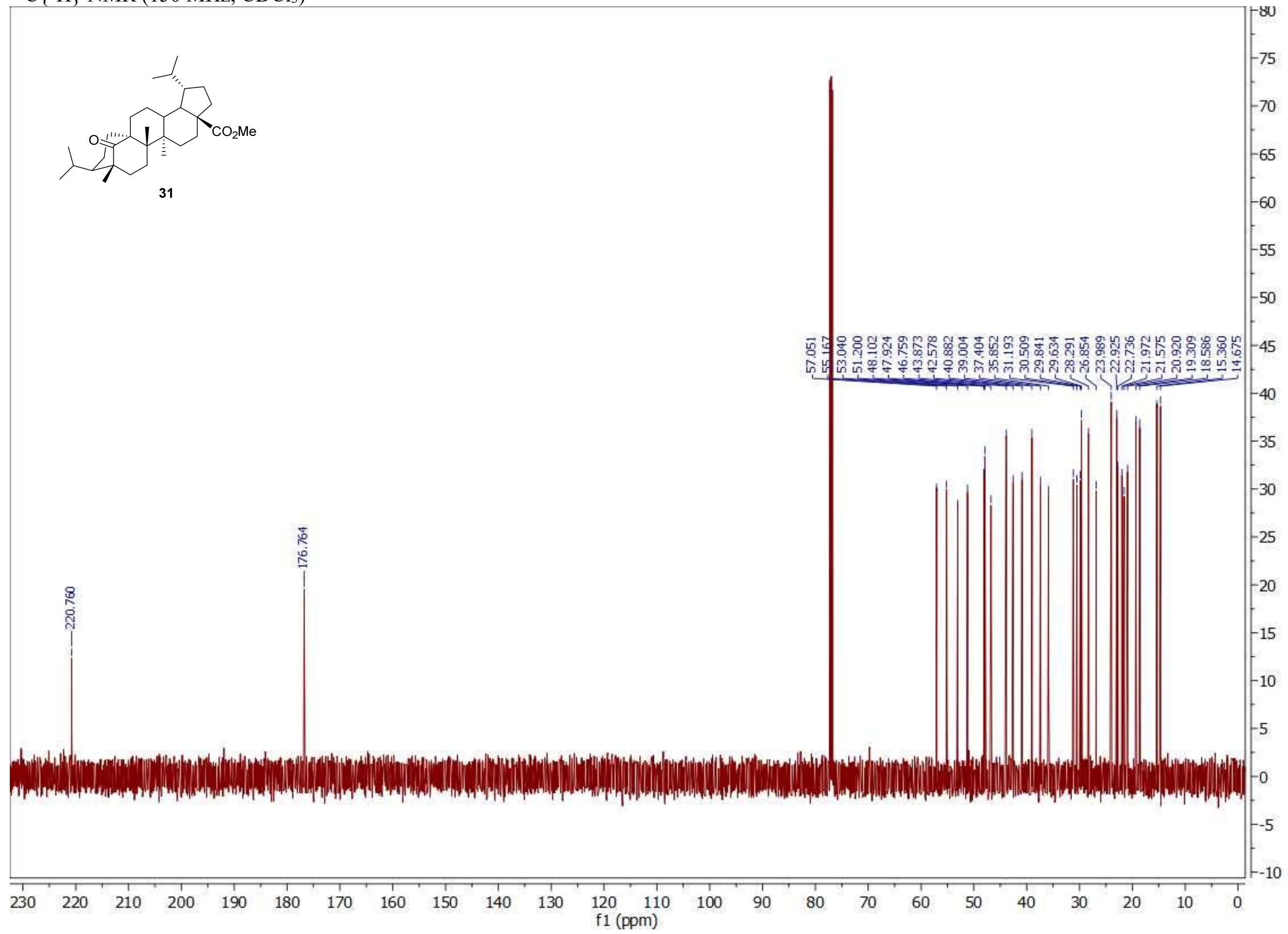


${ }^{1} \mathrm{H}$ NMR (600 MHz, $\left.\mathrm{CDCl}_{3}\right)$

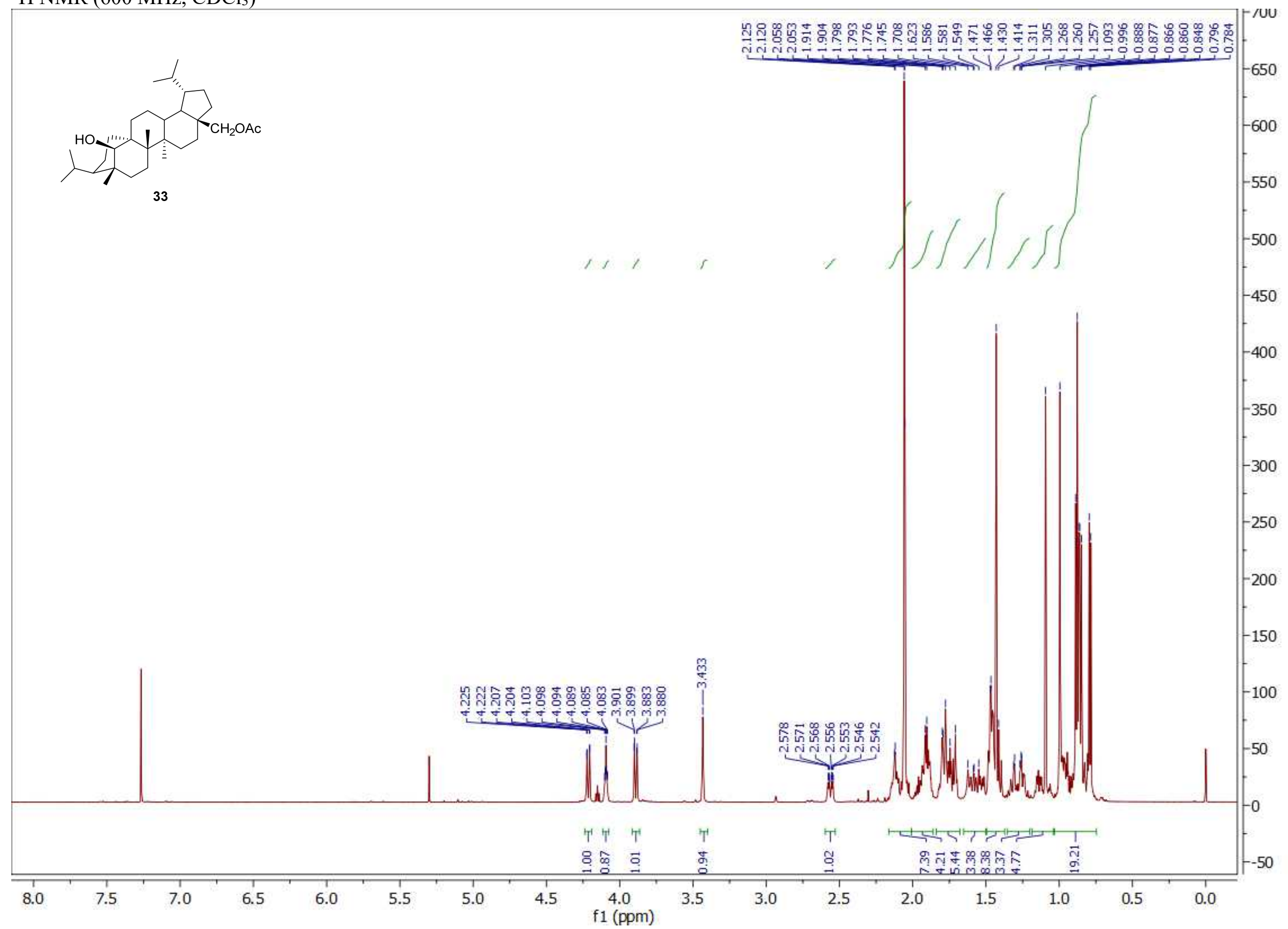


${ }^{13} \mathrm{C}\left\{{ }^{1} \mathrm{H}\right\}$ NMR $\left(150 \mathrm{MHz}, \mathrm{CDCl}_{3}\right)$

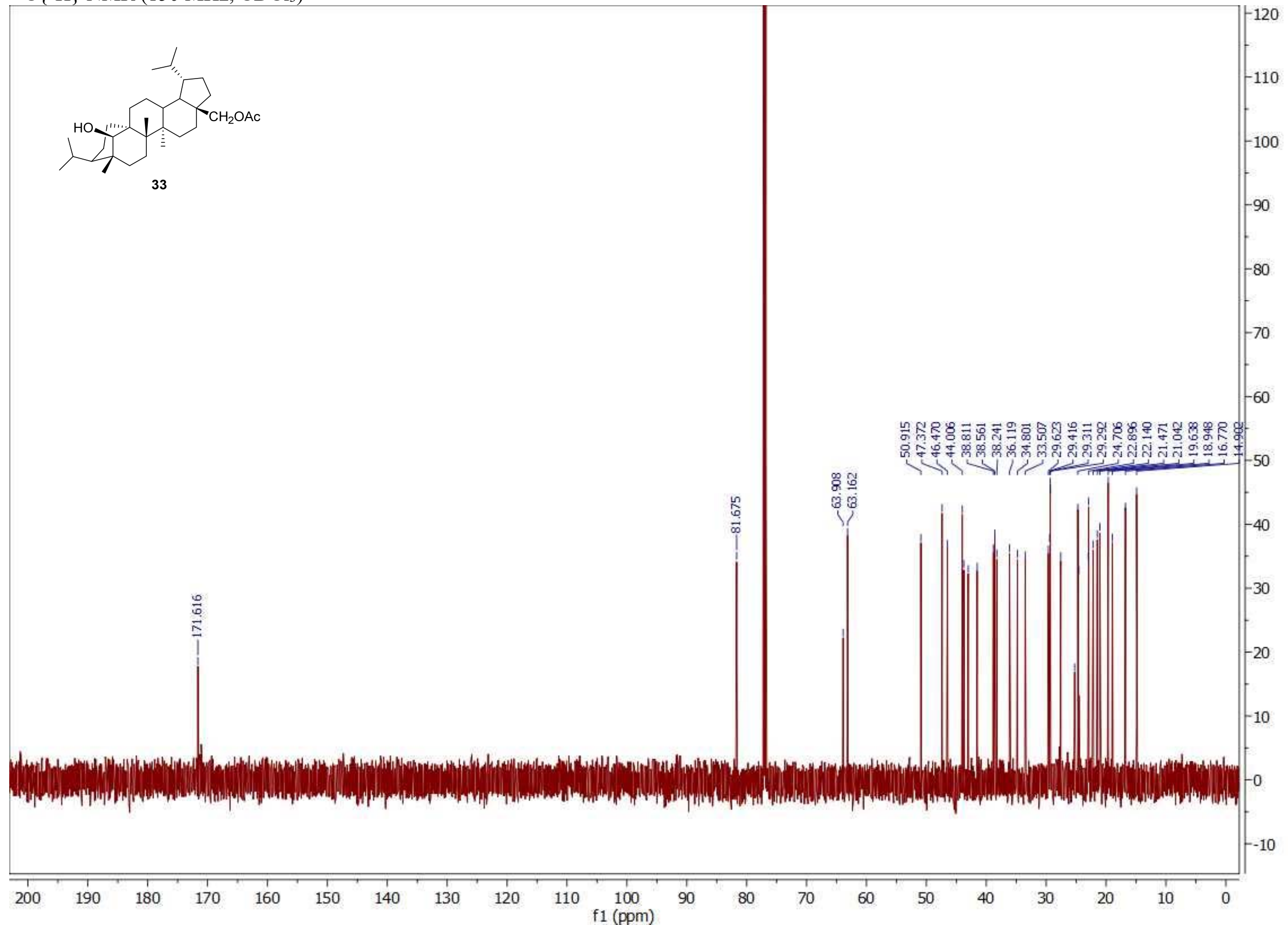


${ }^{1} \mathrm{H}$ NMR $\left(600 \mathrm{MHz}, \mathrm{CDCl}_{3}\right)$

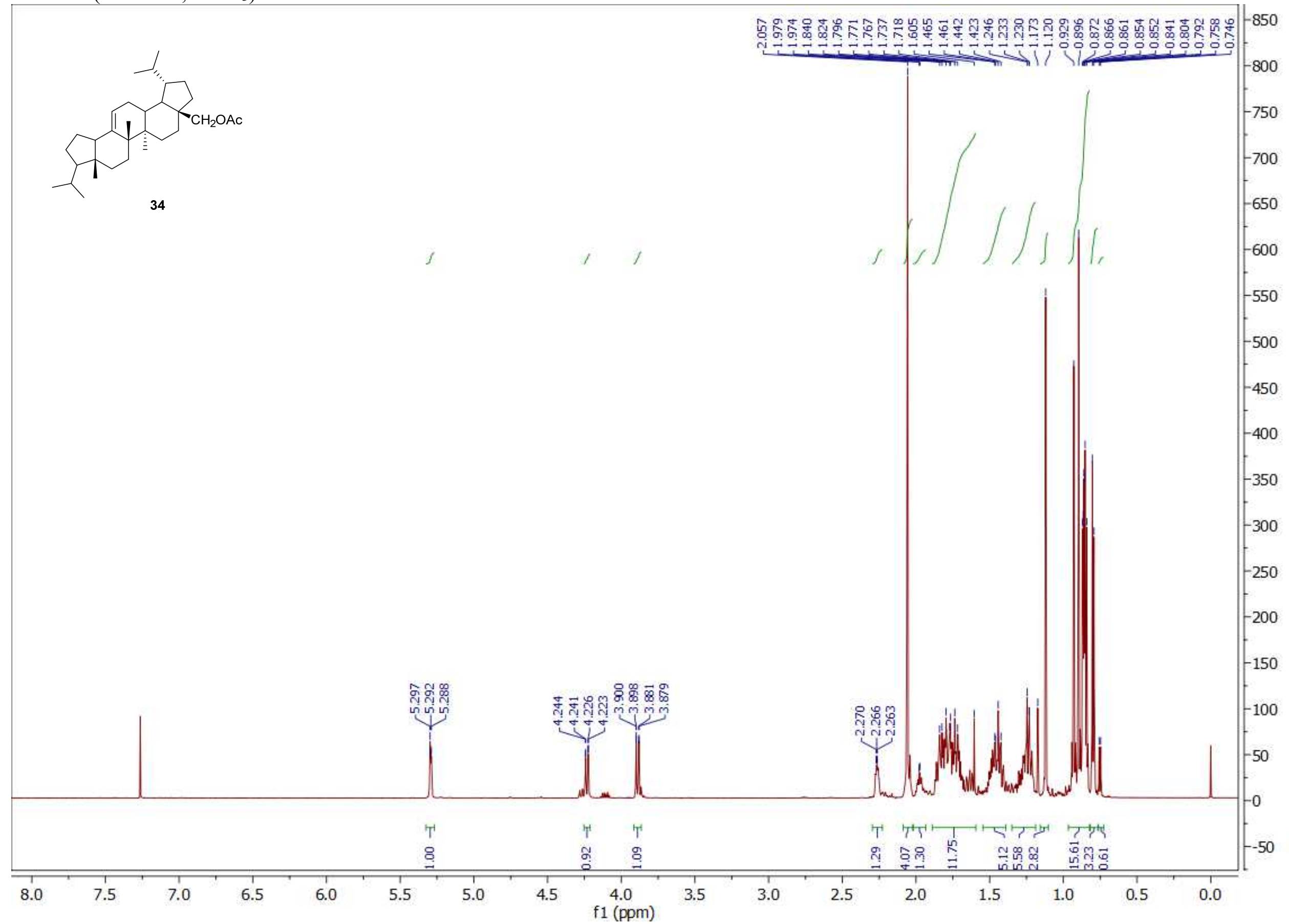


${ }^{13} \mathrm{C}\left\{{ }^{1} \mathrm{H}\right\}$ NMR $\left(150 \mathrm{MHz}, \mathrm{CDCl}_{3}\right)$

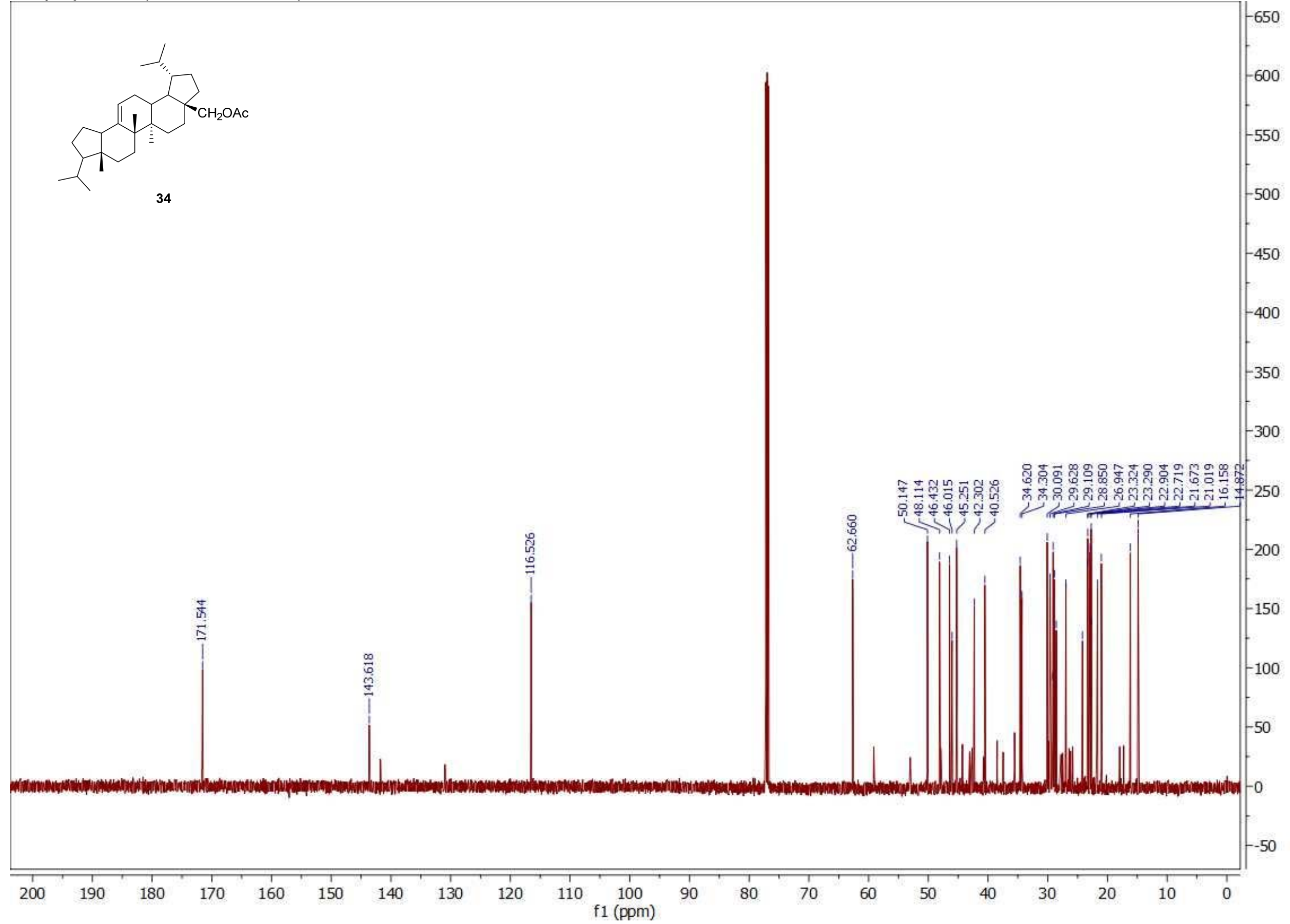

